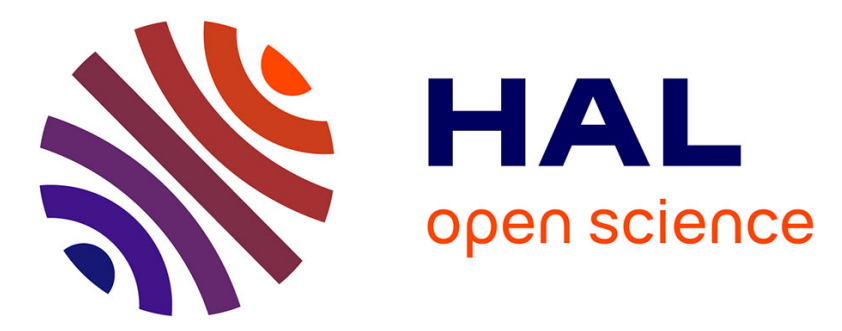

\title{
Surface temperature measurement of a copper anode submitted to a non-stationary electric arc in air
}

\author{
R. Landfried, T. Leblanc, R. Andlauer, Ph. Teste
}

\section{To cite this version:}

R. Landfried, T. Leblanc, R. Andlauer, Ph. Teste. Surface temperature measurement of a copper anode submitted to a non-stationary electric arc in air. European Physical Journal: Applied Physics, 2011, 56 (3), pp.30801. 10.1051/epjap/2011110058 . hal-00751654

\section{HAL Id: hal-00751654 \\ https://hal.science/hal-00751654}

Submitted on 14 Nov 2012

HAL is a multi-disciplinary open access archive for the deposit and dissemination of scientific research documents, whether they are published or not. The documents may come from teaching and research institutions in France or abroad, or from public or private research centers.
L'archive ouverte pluridisciplinaire HAL, est destinée au dépôt et à la diffusion de documents scientifiques de niveau recherche, publiés ou non, émanant des établissements d'enseignement et de recherche français ou étrangers, des laboratoires publics ou privés. 


\title{
Surface temperature measurement of a copper anode submitted to a non stationary electric arc in air - Contribution to the assessment of the power balance.
}

\author{
R. Landfried, T. Leblanc, R.Andlauer, Ph. Teste \\ Laboratoire de Génie Electrique de Paris : SUPELEC - CNRS - Universités Paris VI et Paris XI - \\ Plateau de Moulon - 91192 Gif sur Yvette Cedex - FRANCE
}

E-mail: teste@1gep.supelec.fr

E-mail: romaric.landfried@lgep.supelec.fr

\begin{abstract}
.
This work concerns the assessment of the surface temperature of copper anodes submitted to an electric arc in a non stationary regime in air at atmospheric pressure. An infrared camera is used to measure the decrease of the surface temperature just after a very fast controlled arc extinction. Results are presented for different mean values of the arc current intensity $(30,70$ and $130 \mathrm{~A}$ ) with an electric arc duration in the range 2-5 ms. The temperature decrease after the arc extinction allows an assessment of the surface temperature just at the moment of the arc switching off. In the present experimental conditions the mean temperatures reached for copper anodes are in the range $750-1200{ }^{\circ} \mathrm{C}$ according to the arc current intensity values. Comparison between experimental results and a numerical modelling of the electrode heating allowed to assess the surface power balance. The values for the volt equivalent are found about $12 \mathrm{~V}$ and the values for the surface power density are found to be near $2 \times 10^{9} \mathrm{~W} / \mathrm{m}^{2}$.
\end{abstract}

Pac's numbers: $52.80 \mathrm{Mg}, 52.50 \mathrm{Nr}, \mathbf{5 2 . 7 7} \mathrm{Fv}, \mathbf{5 2 . 7 5} \mathrm{Hn}$

Key Words: Electric arc, power balance, electrode erosion

Short Title: Surface temperature assessment of a copper anode 


\section{1- Introduction}

The experimental measurement of the surface temperature of an electrode submitted to a nonstationary electric arc burning in air at atmospheric pressure would be useful in many scientific or technological fields. For instance, it would be a very useful tool as well for the improvement of the knowledge of the arc-electrode interaction or for the conception of high performance electrode material according to the applications.

However, until now this parameter seems to be relatively unknown in the previous experimental conditions. Many experimental researches have been conducted in the case of stationary arcs burning in argon with refractory electrodes (tungsten, thoriated tungsten, hafnium ...) [1-4]. Under these conditions, the methods used to measure surface temperature depend strongly on the stationary and motionless character of the arc. In [1-6], optical methods were used such as a single color and a double color pyrometry method. The stability of the arc root on the electrode surface and the arc column symmetry were often an essential parameter to allow the temperature measurement.

The aim of this work is to obtain information concerning the spatial distribution of the anode surface temperature and about the power balance at the anode surface.

A method is proposed to assess the surface temperature of a copper (low melting temperature) anode in the case of a switching arc (non stationary regime) burning in air at atmospheric pressure with an electric current intensity in the range $30-130 \mathrm{~A}$ and a duration in the range $2.5-5 \mathrm{~ms}$.

The paper is organized as follows:

The first part describes the experimental device used to create opening electric arcs while the second part discusses the experimental method used to measure the temperature.

In the third part, some experimental results are presented. Some typical surface temperature distributions are presented for various arc current intensities and for the different arc behaviors observed. The influence of arc current intensities on temperature profiles is briefly presented. The decrease of surface temperature after the arc extinction is then studied. An assessment of the surface temperature at the moment of the arc extinction is proposed for three different mean arc current intensities.

In the last part a numerical modelling of the electrode heat balance is presented and the calculated temperature distributions are compared with the experimental results. This method allows to assess, for two simple cases, the main characteristics of the power balance at the anode surface (power and surface power density).

\section{2- Description of the experimental device}


The experimental device used to measure the temperature of the electrode surface may be divided into two parts:

- The electrical device which consisted of the power supply, the load circuit and the electronic switching system. It is schematically presented in figure 1.

- The electromechanical system which opened the contact and the different cameras used to observe the arc behavior and to measure the surface temperature. It is schematically presented in figure 2 .

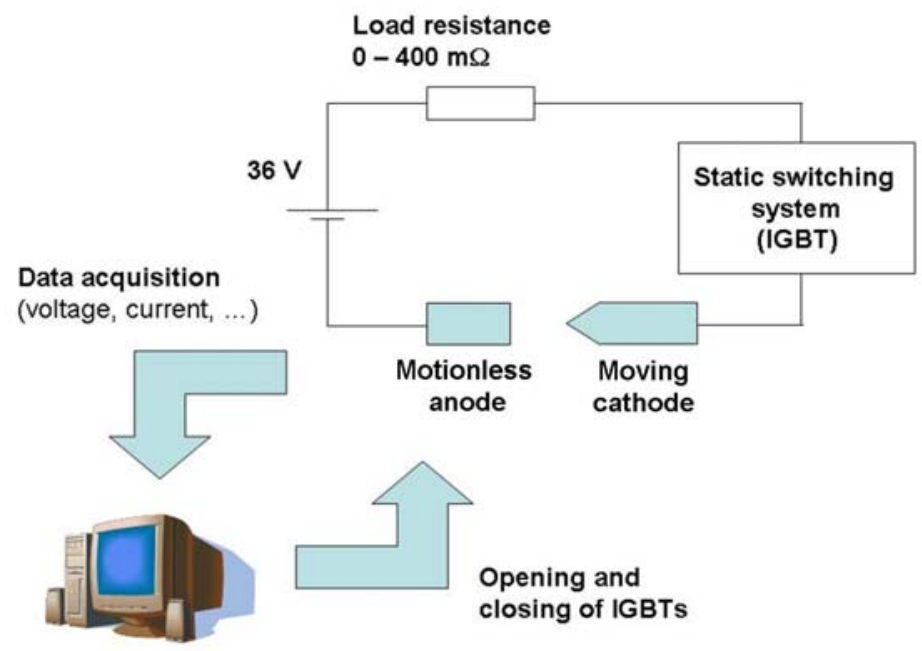

\section{Electrical device}

Figure 1. Schematic description of the electrical part of the experimental device

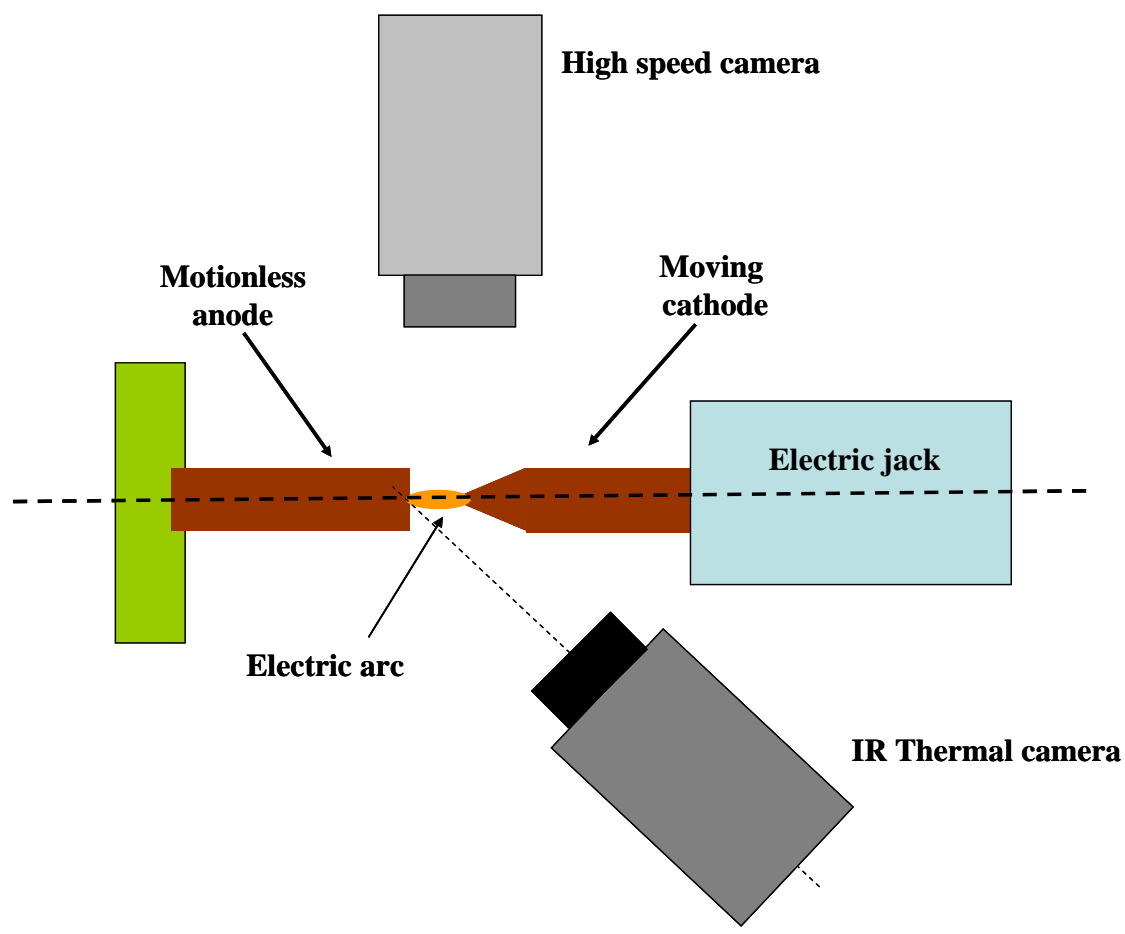

Figure 2. Schematic description of the experimental device. 


\section{1-The electrical device}

The power supply, already described in [7,8], consists of a set of three $12 \mathrm{~V}$ electric batteries. The internal resistance of the batteries was about $18 \mathrm{~m} \Omega$. An electronic device, consisting of IGBTs (Insulated Gate Bipolar Transistors) allowed control of the current in the circuit and was also used to extinguish the arc. This static device may switch off a current intensity as high as $1500 \mathrm{~A}$ in less than a microsecond and may dissipate up to $275 \mathrm{~J}$. The load in the circuit was a non-inductive adjustable resistance (0 to $400 \mathrm{~m} \Omega)$.

\subsection{The mechanical device}

Two coaxial electrodes constitute the contact. The anode is a flat-faced cylinder and remains in a fixed position. In order to increase the observable area on the flat electrode when the contact is open, a conical shape was chosen for the moving electrode (the cathode).

A photograph, presented in figure 3 and taken before the arc, illustrates the position and the shapes of the two electrodes. An electric servomotor is used to open the contact with nearly constant velocity.

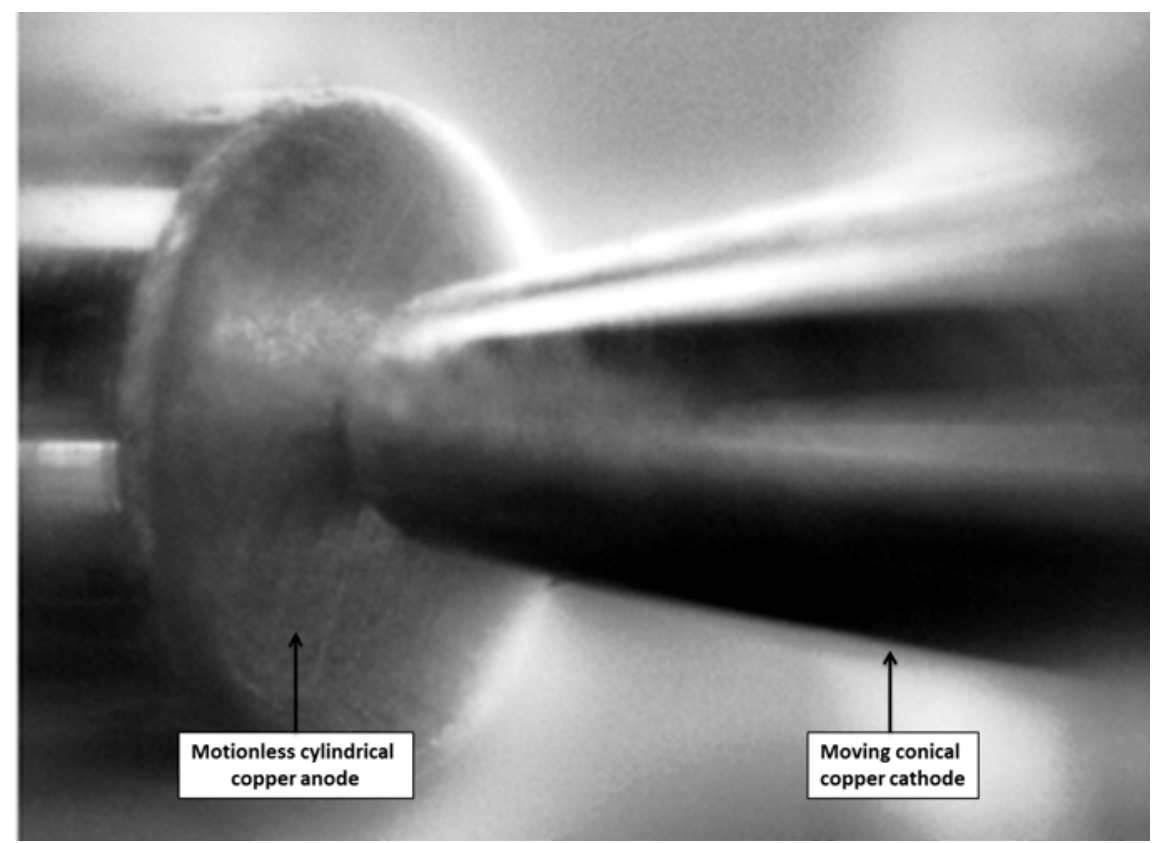

Figure 3. Photography of the electrodes before the arc: the contact is closed.

\section{Measurements and description of the method}

During arcing the following parameters were recorded:

The current intensity.

The arc voltage.

The electrode gap distance. 
The light emitted by the plasma prevents to observe the cathode surface during arcing. Our process is to measure the surface temperature after the arc extinction. This measurement requires an accurate spatial resolution and a short exposure time to limit the temperature variations during the measurement. That means the use of a pyrometer is not well appropriated because of its long integration time (1 ms) and because it only gives the mean temperature of its spot (no distribution). An infrared camera was used to measure the temperature distribution on the flat motionless anode surface. The spectral response of the InSb camera detector was in the range of $3.7 \mu \mathrm{m}-4.8 \mu \mathrm{m}$. The matrix detector was 320 by 240 pixels. The optic used allowed a spatial resolution of $40 \mu \mathrm{m}$ to $60 \mu \mathrm{m}$ by pixel. The first operation to achieve was to calibrate this camera for copper electrodes. It was made with the help of a specific device which allowed to calibrate precisely the camera until copper melting temperature. A special attention was brought to the surface state of the anode before each arc. The aim was to have the same surface state as the one of the samples used for the camera calibration. The copper samples used for calibration had an oxidised surface which is similar to the surface of electrodes used for arcing. An average calibration curve (for different surface states) was obtained. Several arguments let think that temperature measurements were made with an oxidised surface:

- The electrode surface after arcing has the same appearance (colour,) than before arcing.

- Moreover we do not observe soot presence on the electrode surface ...

- The decomposition temperatures of the oxides are in the range of [1600 K - $2100 \mathrm{~K}]$.

- An order of magnitude of the kinetic of oxide formation for temperatures in the range of [500 K $-1200 \mathrm{~K}$ ], according to [9] is approximately $1 \mathrm{~nm}$ for $10 \mu \mathrm{s}$.

With all these elements, the assumptions were made that the surface oxidation does not change strongly our calibration curve which was obtained for different surface states of oxidised electrodes. The electronic system allowed to force the electric arc extinction in less than $1 \mu$ s (this duration is denoted $\left.\tau_{\text {elec }}\right)$.

The electronic control developed with the infrared camera allowed to activate this one with a time delay of $15 \mu$ s (this duration is denoted $\tau_{\text {activate }}$ ) and has a precision less than $0.1 \mu \mathrm{s}$. The exposure time

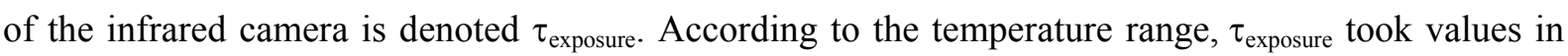
the range of $[10 \mu \mathrm{s}, 120 \mu \mathrm{s}]$.

Hereafter, $\tau_{\text {image }}$ will be defined as the instant for which the photography is taken and is given by:

$$
\tau_{\text {image }}=\tau_{\text {elec }}+\tau_{\text {activate }}+\frac{1}{2} \tau_{\text {exp osure }}
$$

These different times are schematically presented in figure 4 . 


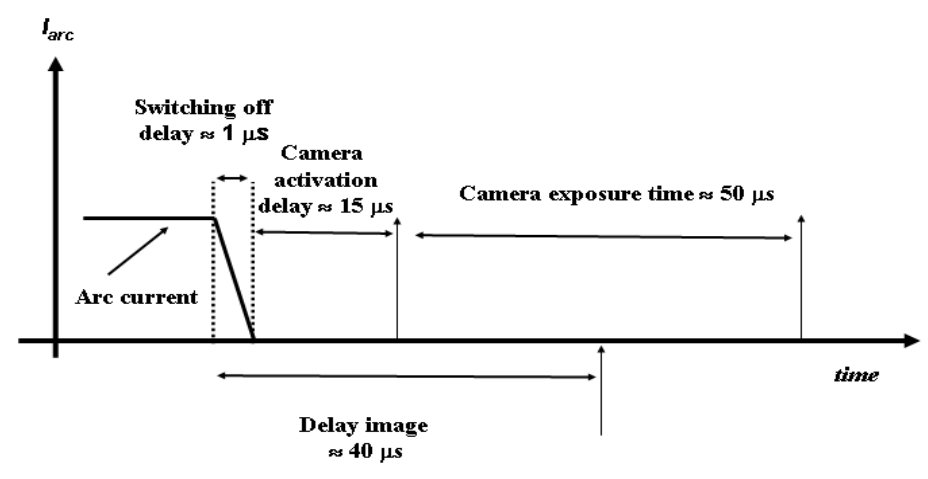

Figure 4. Description of the different delays for $\tau_{\text {exposure }}=50 \mu \mathrm{s}$ and $\tau_{\text {image }}=40 \mu \mathrm{s}$.

As an exposure time was required, it was impossible to have a temperature measurement which represented the temperature value at a given instant. The measure corresponded to the averaged temperature during the measurement duration. Obviously, during the measurement time $\left(\tau_{\text {exposure }}\right)$ the surface temperature may vary. These variations were all the less important since $\tau_{\text {exposure }}$ was short. In most of the presented cases, $\tau_{\text {exposure }}$ was equal to $50 \mu \mathrm{s}$.

The electrode material was OFHC copper (Oxygen Free High Conductivity). The bath gas was air at atmospheric pressure. The diameter of the electrodes was $8 \mathrm{~mm}$. The conical electrode had a half angle at the top equal to $30^{\circ}$. Moreover, an electric jack was chosen in order to allow a precise synchronization $(<0.1 \mu \mathrm{s})$ between the motion and the IR camera. Consequently, this choice limited the opening velocity.

The process of opening operation was as follows:

When the IGBTs and the contact were closed, a DC current was flowing through the electrical circuit. When the contact opened the current dropped rapidly and became stable around its mean value denoted $\mathrm{I}_{\mathrm{arc}}$. For instance, in figure 5, the current drops from $130 \mathrm{~A}$ to $70 \mathrm{~A}$ in less than $200 \mu \mathrm{s}$. Then, it decreases slowly during arcing until the arc extinction. At this instant, its value was equal to 80-90 $\%$ of $\mathrm{I}_{\text {arc }}$. The contact voltage increased at the contact opening up to the arc voltage value and remained quite stable during the arc. The arc duration was controlled by the IGBTs triggering which depended on the software control for which existed an uncertainty of $2 \mathrm{~ms}$. For each opening, the data were automatically recorded. Figure 5 presents typical evolution for contact voltage and current intensity during the contact opening. The electrode gap at the switching off was about $3.5 \mathrm{~mm}$. 


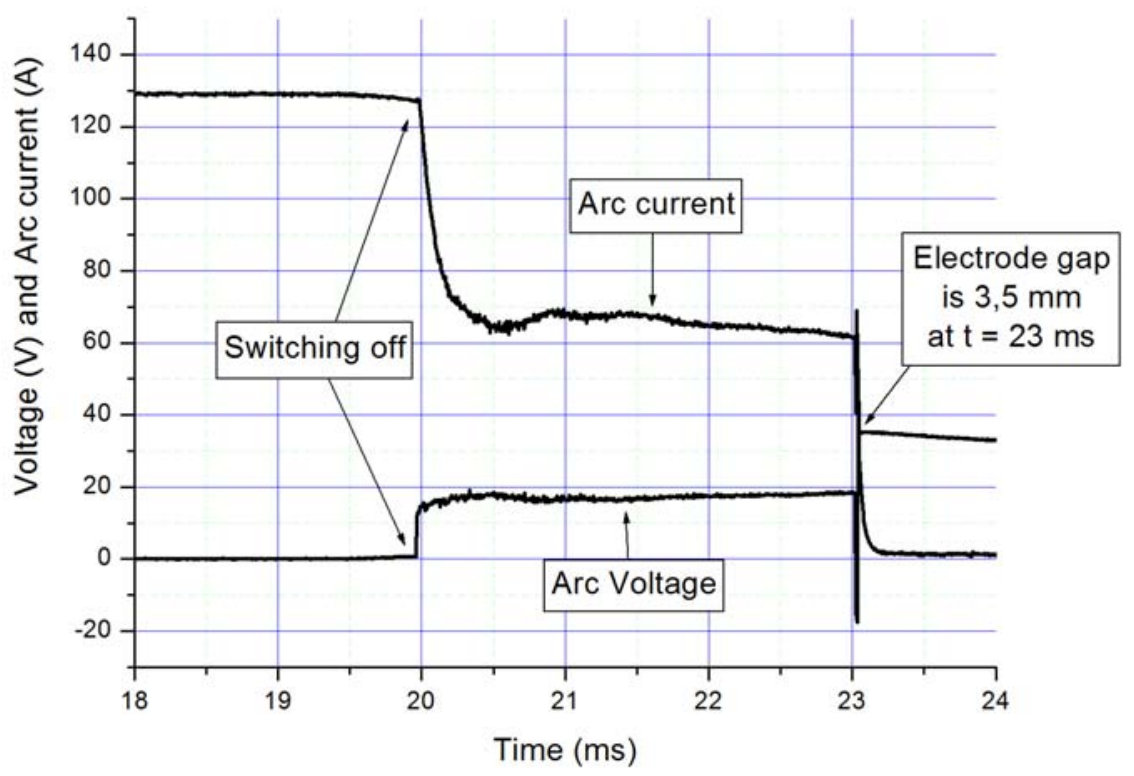

Figure 5. Typical time evolution of arc voltage and arc current intensity.

\section{Experimental results}

\subsection{Preliminary remarks and first observations.}

At the moment of the arc extinction, we have measured both the electrode surface temperature and the discharge gas temperature with the IR camera. The observed discharge temperature was far lower than the minor boundary of the range of valid temperature values whereas the anode surface temperature was in the range. It means the arc radiation was negligible compared to the anode radiation in the IR camera wavelength range. As mentioned above, the spatial resolution of the IR camera was about 50 $\mu \mathrm{m}$ by $50 \mu \mathrm{m}$ and an integration delay in the range of $10-120 \mu$ s was required. Then, events occurring at a smaller time or space may not be detailed by an IR photography. For instance, the heating which results from the possible existence of microscopic spots having short life durations is averaged in time and space. As a result of spatial averaging, the temperature measured by the camera at the scale of a pixel can be quite less than the temperature reached locally at the scale of a micro-spot. In figure 6 , an image of an anode surface damaged by an arc, obtained with a 3D optical profilometer, is presented. Different scales of structures may be observed:

- Very numerous microscopic craters with diameters between 10 and $20 \mu \mathrm{m}$. They may result from the heating of numerous dispersed micro-spots.

- A macroscopic crater with diameter of some hundreds micrometers. It may results from the heating of a multitude of grouped micro-spots. 


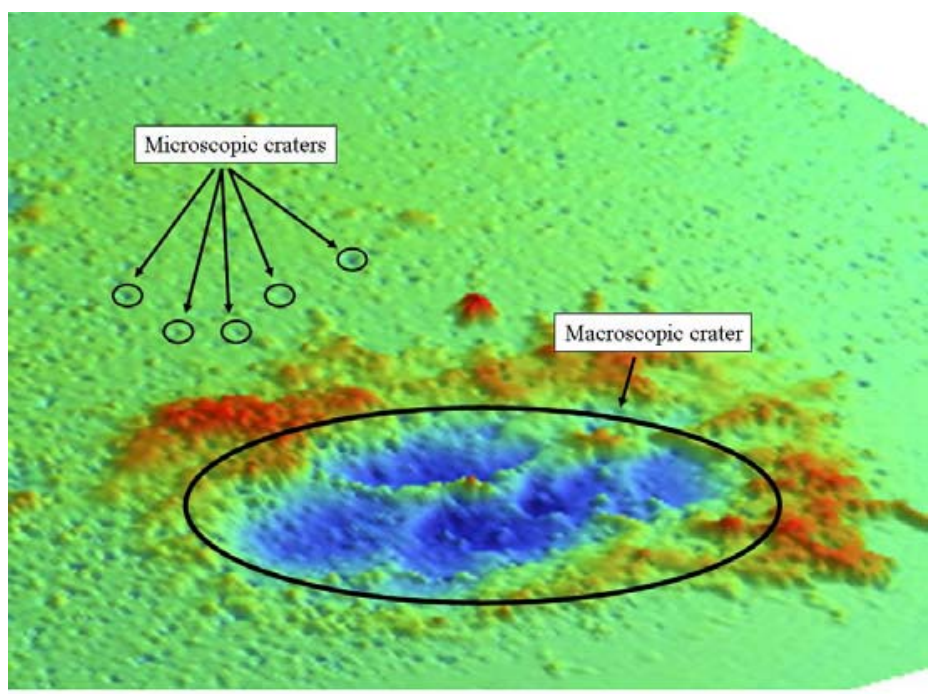

Figure 6. Example of a macroscopic crater and of a multitude of microscopic craters due to very localized heating.

\subsection{Examples of surface temperature distributions for several arc current levels.}

In this part some examples of typical surface temperature distributions are presented. The experimental conditions were:

- $\quad \tau_{\text {image }}=75 \mu \mathrm{s}, \mathrm{I}_{\mathrm{arc}}=37 \mathrm{~A}$, arc duration $=5.6 \mathrm{~ms}$ in figure $7(\mathrm{a})$

- $\quad \tau_{\text {image }}=40 \mu \mathrm{s}, \mathrm{I}_{\text {arc }}=67 \mathrm{~A}$, arc duration $=3.8 \mathrm{~ms}$ in figure 8

- $\tau_{\text {image }}=20 \mu \mathrm{s}, \mathrm{I}_{\text {arc }}=122 \mathrm{~A}$, arc duration $=5.6 \mathrm{~ms}$ in figure 9(a)

Moreover, for the cases of figures 7(a) and 9(a), a 3D optical profilometer has been used to obtain a topological image of the surface after the arc.

Different behaviors have been observed:

- In figure 8, the anode arc root remained motionless during the last two milliseconds of arcing. Plus, the arc root displacement was about $0.5 \mathrm{~mm}$. A single heated area was discernible. The temperature distribution was regular and practically axi-symmetric.

- In figure 7(a) the electric arc has moved by jump just before switching off. Indeed, two heated zones were discernable. They corresponded to the two craters observable in figure $7(b)$.

- In figure 9, the arc has moved continuously before its extinction. A larger area has been heated. The size and the shape of the crater in figure $9(\mathrm{~b})$ were of the same order of magnitude than the heated area. 


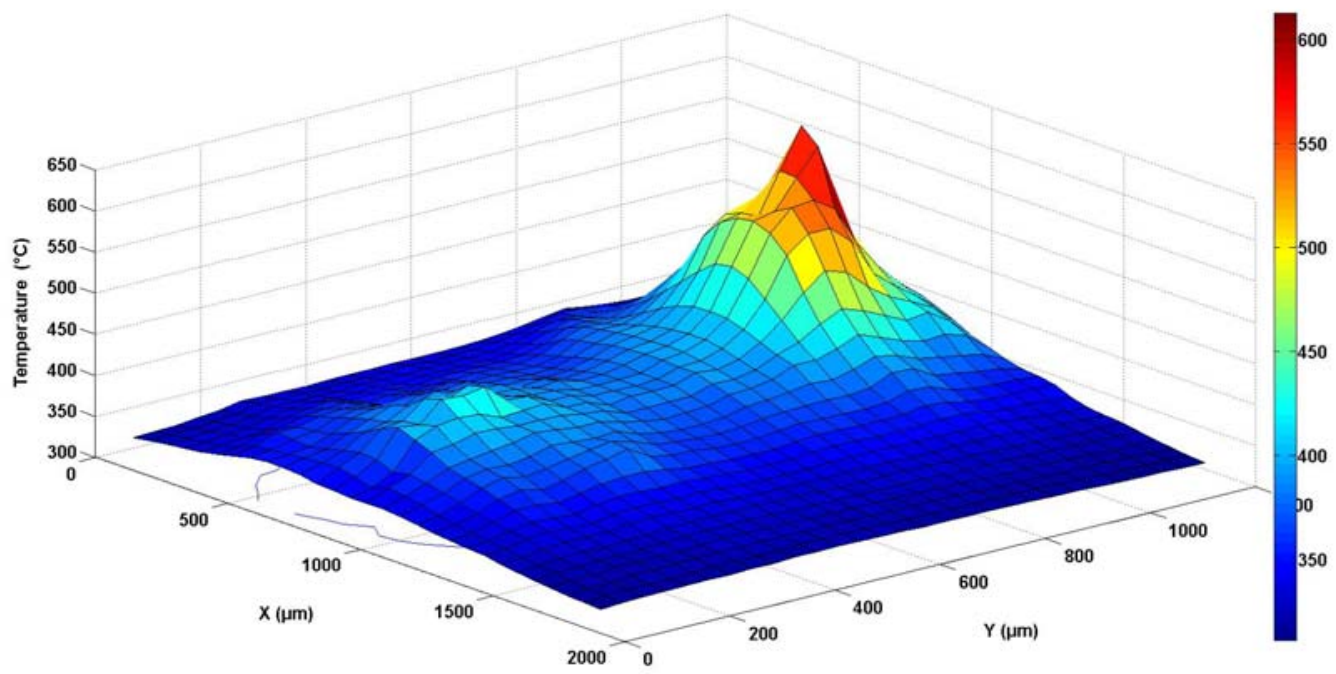

Figure 7(a). Example of surface temperature distribution in the case of a jumping arc.

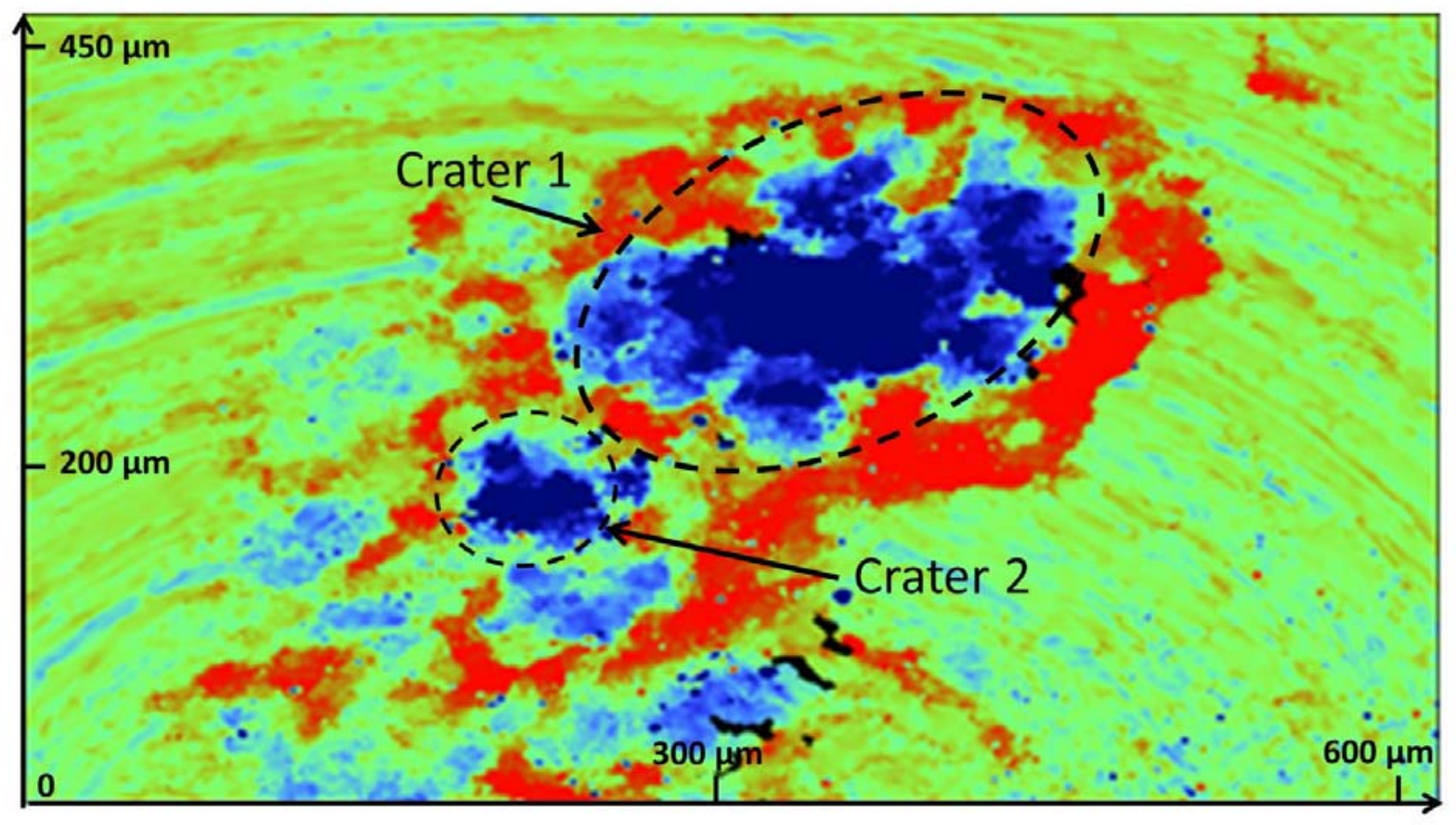

Figure 7(b). Example of surface topology after a jumping arc 


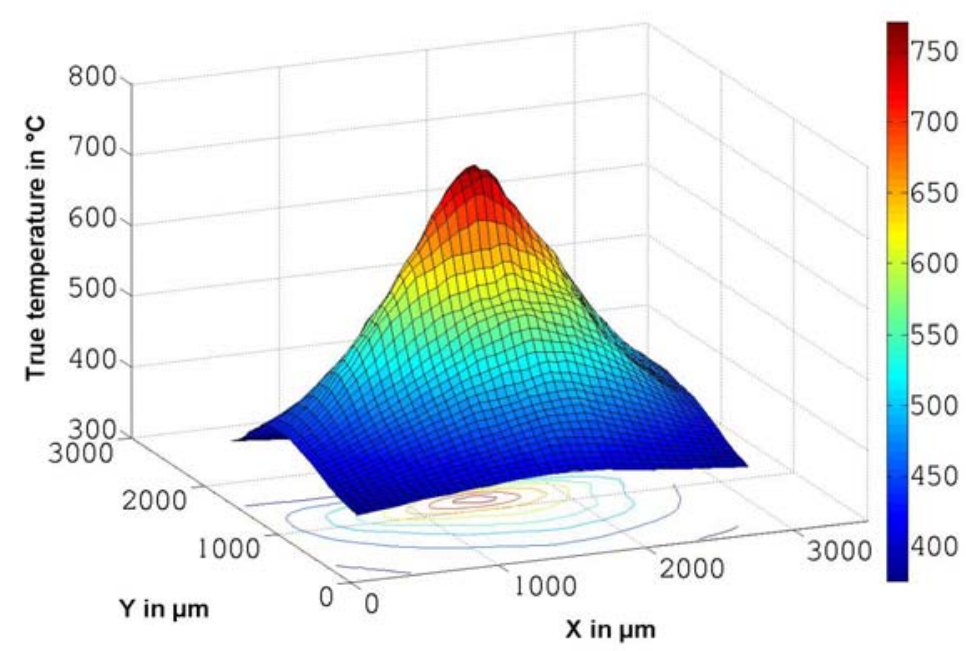

Figure 8. Example of surface temperature distribution in the case of a motionless arc.

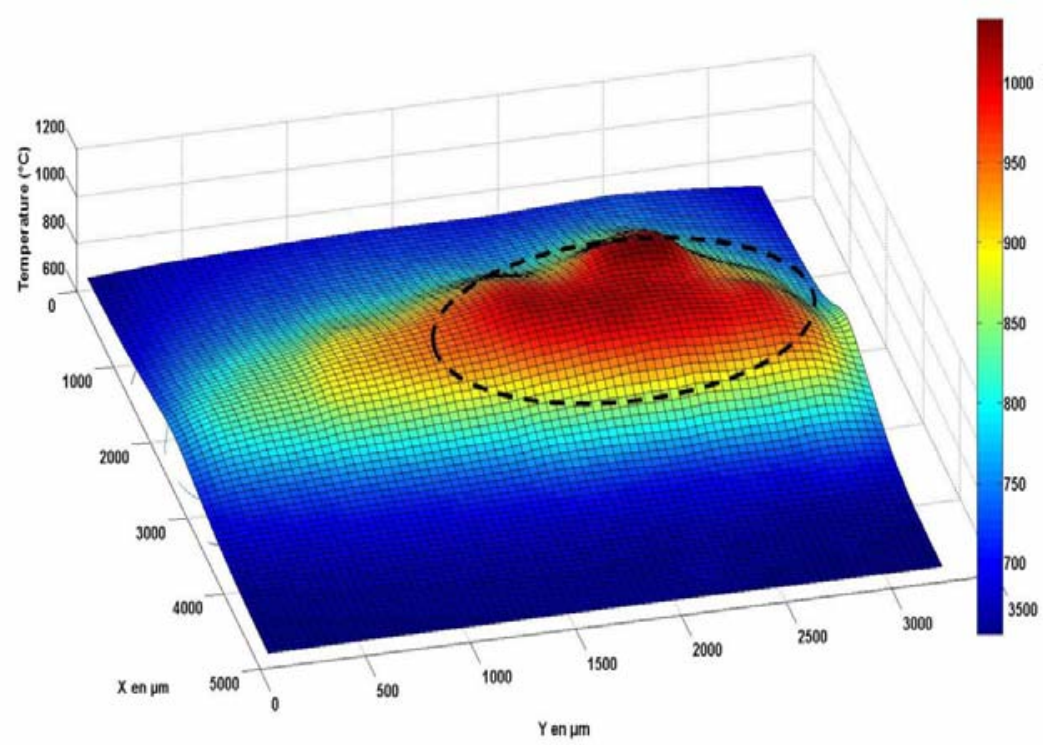

Figure 9(a). Example of surface temperature distribution in the case of an arc in continuous motion. 


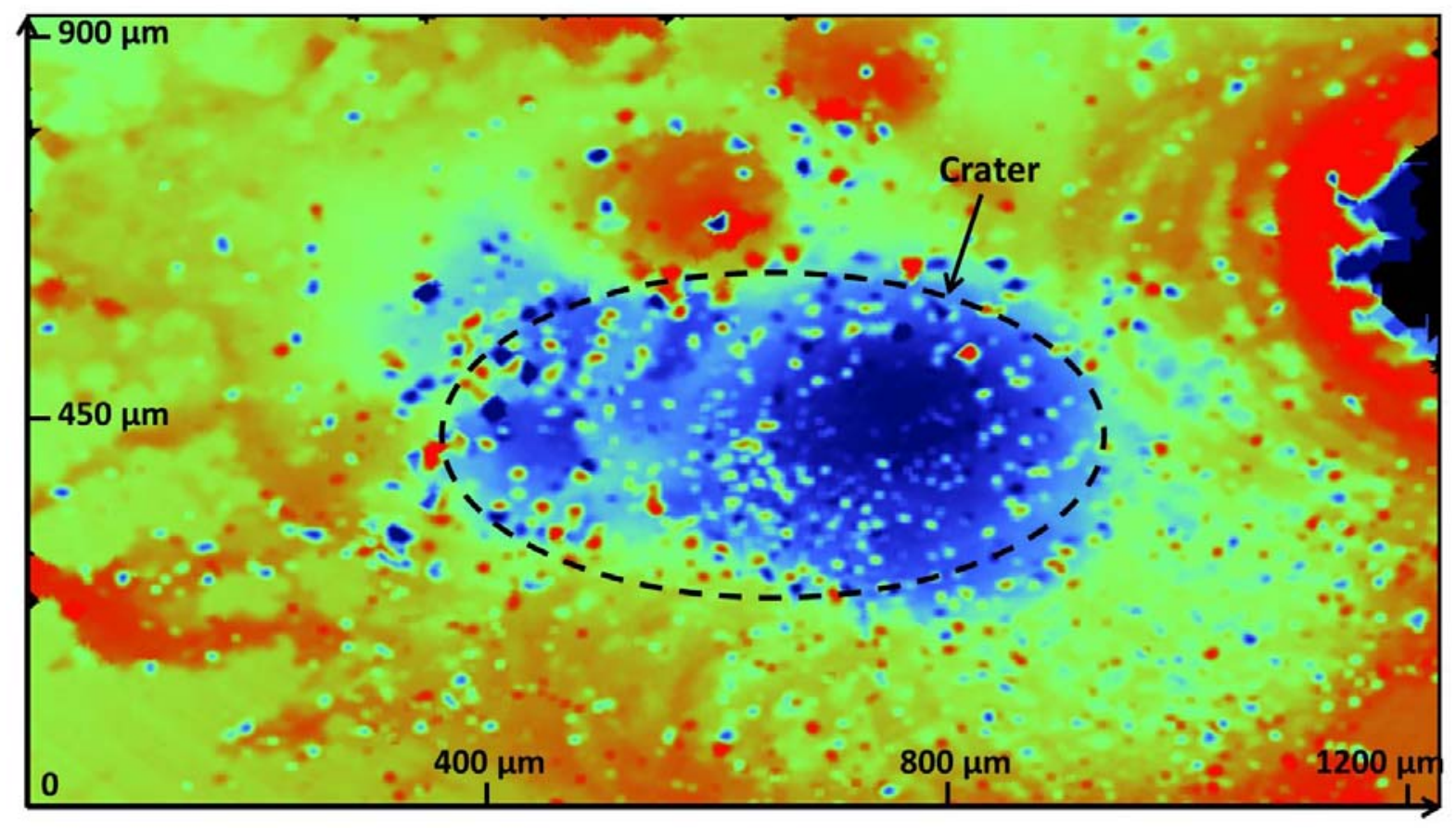

Figure 9(b). Example of surface topology after an arc in continuous motion (fig.9(a)).

4.3 Example of surface temperature profiles for various current intensities and $\tau_{\text {image }}$ values

\subsubsection{Influence of the arc current intensity on the electrode heating:}

In figure 10 two surface temperature profiles were plotted for motionless arc on the anode. They correspond to the following experimental conditions:

- Profile ${ }^{\circ} 1$ : the average current $\mathrm{I}_{\text {arc }} \approx 43 \mathrm{~A}$ and $\tau_{\text {image }}=40 \mu \mathrm{s}$.

- Profile $\mathrm{n}^{\circ} 2: \mathrm{I}_{\text {arc }} \approx 131 \mathrm{~A}$ and $\tau_{\text {image }}=20 \mu \mathrm{s}$. 


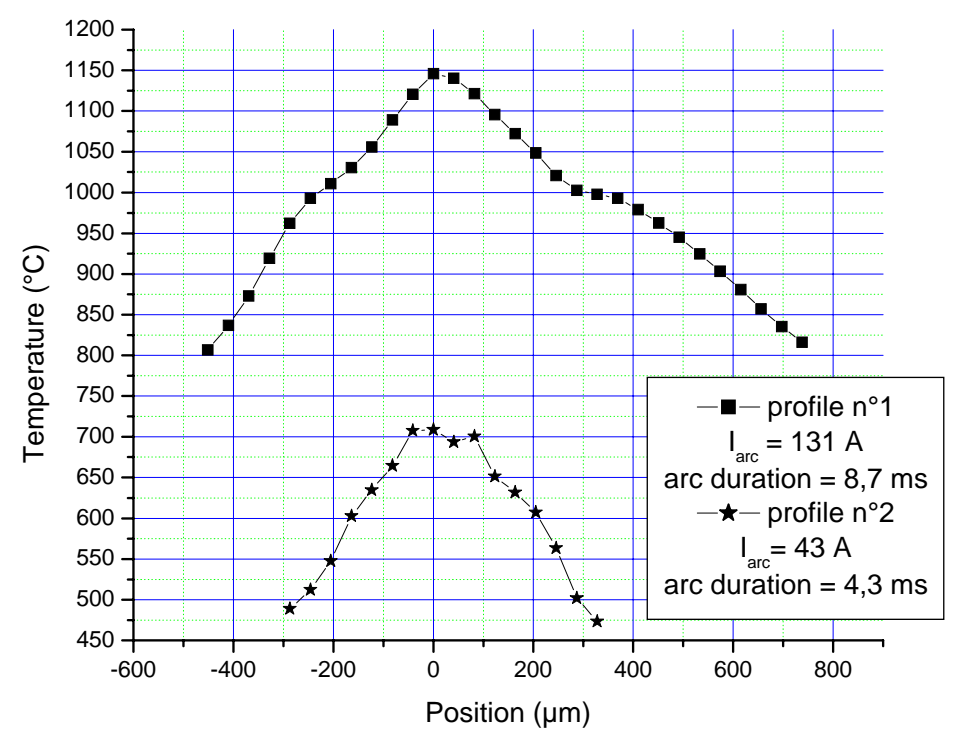

Figure 10. Two temperature profiles for two arc current intensities: $I_{\text {arc }}=43 \mathrm{~A}$ and $131 \mathrm{~A}$.

These two profiles are typical profiles which permit to quantify the influence of arc intensity and duration in the case of motionless arcs. We can observe that the temperature distribution in the case of profile 1 is not only larger but has also a maximum temperature $450{ }^{\circ} \mathrm{C}$ higher than the profile 2 .

\subsubsection{Observation of the temperature decrease with time.}

The temperature profiles were investigated for:

- An average arc current $\mathrm{I}_{\text {arc }} \approx 70 \mathrm{~A}$

- $\quad$ Arc durations $d t$ in the range $3 \mathrm{~ms}-4 \mathrm{~ms}$

- Various values of $\tau_{\text {image }}(40 \mu \mathrm{s}, 200 \mu \mathrm{s}, 500 \mu \mathrm{s}$ and $1 \mathrm{~ms})$ in order to observe the temperature decrease after the arc extinction and then to propose an assessment of the surface temperature at the instant of the arc extinction.

For each $\tau_{\text {image }}$ value about ten measurements were made.

An example of several surface temperature profiles measured for different arcs and various $\tau_{\text {image }}$ values is proposed in figure 11. In each case the values of $\tau_{\text {image }}$ and $\mathrm{T}_{\max }$ are given.

Results for $\tau_{\text {image }}=40 \mu \mathrm{s}$

For the measurements made for $\tau_{\text {image }}=40 \mu \mathrm{s}$, the mean maximum temperature reached on the anode surface $\left(\mathrm{T}_{\max }\right)$ was equal to $750{ }^{\circ} \mathrm{C}$. In the example of figure $11, \mathrm{~T}_{\max }$ was measured equal to $771{ }^{\circ} \mathrm{C}$. Although the arc durations and the average arc current intensities were quite close for all the cases, an 
important dispersion in the $\mathrm{T}_{\max }$ values was observed. $\mathrm{T}_{\max }$ was found in the range $620{ }^{\circ} \mathrm{C}-825{ }^{\circ} \mathrm{C}$. Different explanations may be proposed for that:

- The arc mobility on the electrode surface (and the arc stagnation time) could be different from one electric arc to another one as it was observed with the high speed camera. Moreover, in two particular cases no stagnation time could be determined because the electric arc seemed to move by jumps or continuously during all the arc duration.

- The arc current at the switching off instant may vary from one arc to another between 48 $\mathrm{A}$ and $62 \mathrm{~A}$ and that changes strongly the electrode heating at the end of the arc.

In all the observed cases, the temperature peak width for $\mathrm{T}=500{ }^{\circ} \mathrm{C}$ was less than $1.5 \mathrm{~mm}$ and for $\mathrm{T}=$ $600{ }^{\circ} \mathrm{C}$ it was less than $900 \mu \mathrm{m}$. The maximum surface temperature gradient value obtained was around $440{ }^{\circ} \mathrm{C} / \mathrm{mm}$.

Results for $\tau_{\text {image }}=200 \mu \mathrm{s}$

In this case $\tau_{\text {exposure }}=50 \mu \mathrm{s}$ and $\tau_{\text {activate }}=175 \mu \mathrm{s}$. The mean maximum temperature reached on the anode surface $\left(\mathrm{T}_{\max }\right)$ was equal to $620^{\circ} \mathrm{C}$. In figure 11 a profile is plotted with $\mathrm{T}_{\max }=550{ }^{\circ} \mathrm{C}$. The maximum surface temperature gradient value obtained was around $310^{\circ} \mathrm{C} / \mathrm{mm}$.

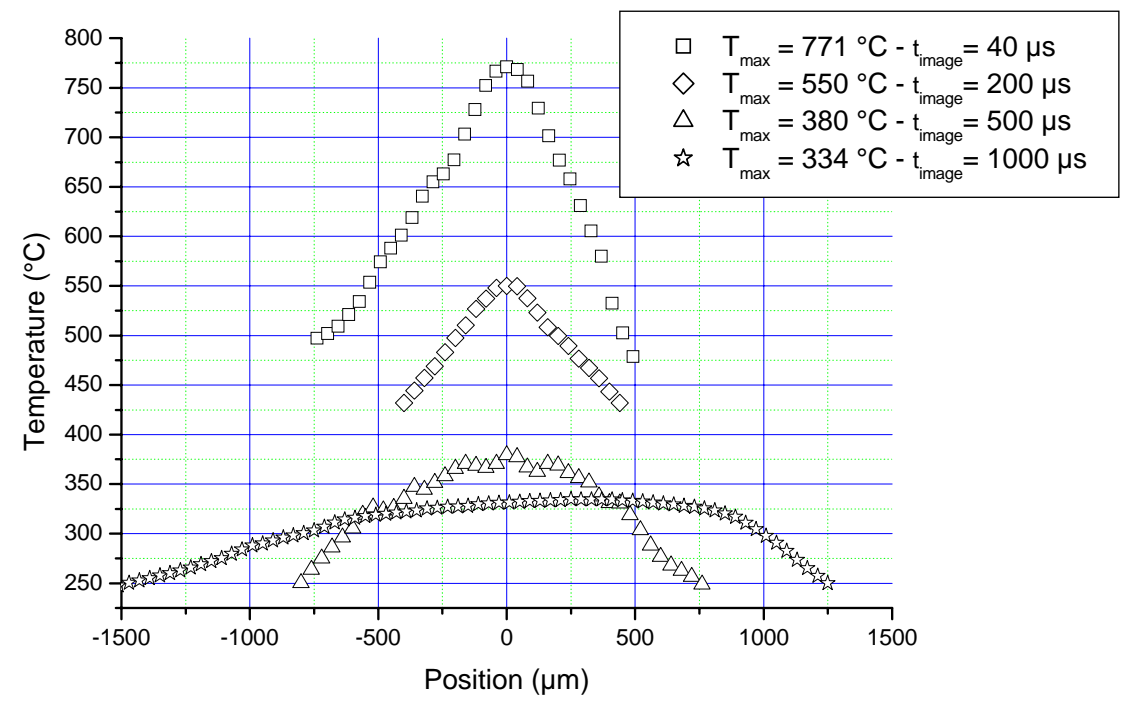

Figure 11. Examples of different surface temperature profiles measured along the diameter of the arc root for $\tau_{\text {image }}=40 \mu \mathrm{s}, 200 \mu \mathrm{s}, 500 \mu \mathrm{s}, 1000 \mu \mathrm{s}$ 
Results for $\tau_{\text {image }}=500 \mu \mathrm{s}$

In this case $\tau_{\text {exposure }}=10 \mu \mathrm{s}$ and $\tau_{\text {activate }}=495 \mu \mathrm{s}$. The mean maximum temperature reached on the anode surface $\left(\mathrm{T}_{\max }\right)$ was equal to $398^{\circ} \mathrm{C}$. In figure 11 a profile has been plotted with $\mathrm{T}_{\max }=380^{\circ} \mathrm{C}$. A typical value of the maximum surface temperature gradient value obtained was around $235^{\circ} \mathrm{C} / \mathrm{mm}$.

Results for $\tau_{\text {image }}=1000 \mu$ s.

In this case $\tau_{\text {exposure }}=10 \mu \mathrm{s}$ and $\tau_{\text {activate }}=995 \mu$ s. The mean maximum temperature reached on the anode surface $\left(\mathrm{T}_{\max }\right)$ was equal to $322^{\circ} \mathrm{C}$. In figure 11 a profile has been plotted with $\mathrm{T}_{\max }=334^{\circ} \mathrm{C}$. A typical value of the maximum surface temperature gradient value obtained was around $175^{\circ} \mathrm{C} / \mathrm{mm}$.

\subsubsection{Assessment of the surface temperature at the time of the arc extinction}

Measurements made gave the surface temperature $40 \mu$ s after the time of the arc extinction. With the help of the temperature evolution with $\tau_{\text {image }}$ it was possible to propose an extrapolation of the surface temperature and then obtain the surface temperature at the extinction time of the electric arc.

In figures 12,13 , and 14 the evolutions of the maximum temperatures versus $\tau_{\text {image }}$ have been plotted for three different values of the average arc current:

- The results presented in figure 12 have been obtained for about 40 arcs. In this case $I_{\text {arc }} \approx$ $30 \mathrm{~A}$ with values in the range $10-44 \mathrm{~A}$ and a standard deviation of $6 \mathrm{~A} . d t \approx 4.8 \mathrm{~ms}$ with values in the range 3-7 ms with a standard deviation of $1 \mathrm{~ms}$.

- The results presented in figure 13 have been obtained for about 60 arcs. In this case $I_{\text {arc }} \approx$ $70 \mathrm{~A}$ with values in the range $59-77 \mathrm{~A}$ and a standard deviation of $4 \mathrm{~A} . d t \approx 3.6 \mathrm{~ms}$ with values in the range $1.7-7 \mathrm{~ms}$ with a standard deviation of $0.9 \mathrm{~ms}$.

- The results presented in figure 14 have been obtained for about $12 \operatorname{arcs}$. In this case $I_{\text {arc }} \approx$ 121 A with values in the range $93-135 \mathrm{~A}$ and a standard deviation of $11 \mathrm{~A}$. $d t \approx 7.6 \mathrm{~ms}$ with values in the range $6.6-8.7 \mathrm{~ms}$ with a standard deviation of $0.7 \mathrm{~ms}$.

In the three cases, the dispersion is also presented. An extrapolation of the results for $\tau_{\text {image }}=0 \mu \mathrm{s}$ allows then to assess the maximum mean temperature at the arc switching off. Then, for $I_{\text {arc }} \approx 29.4 \mathrm{~A}$, $T_{\max }(t=0 \mu s) \approx 785^{\circ} \mathrm{C}$ was obtained. It should be emphasized that the temperature decrease during the first $40 \mu$ s after the switching off may be very important (several tenth of degrees up to $100{ }^{\circ} \mathrm{C}$ ). 


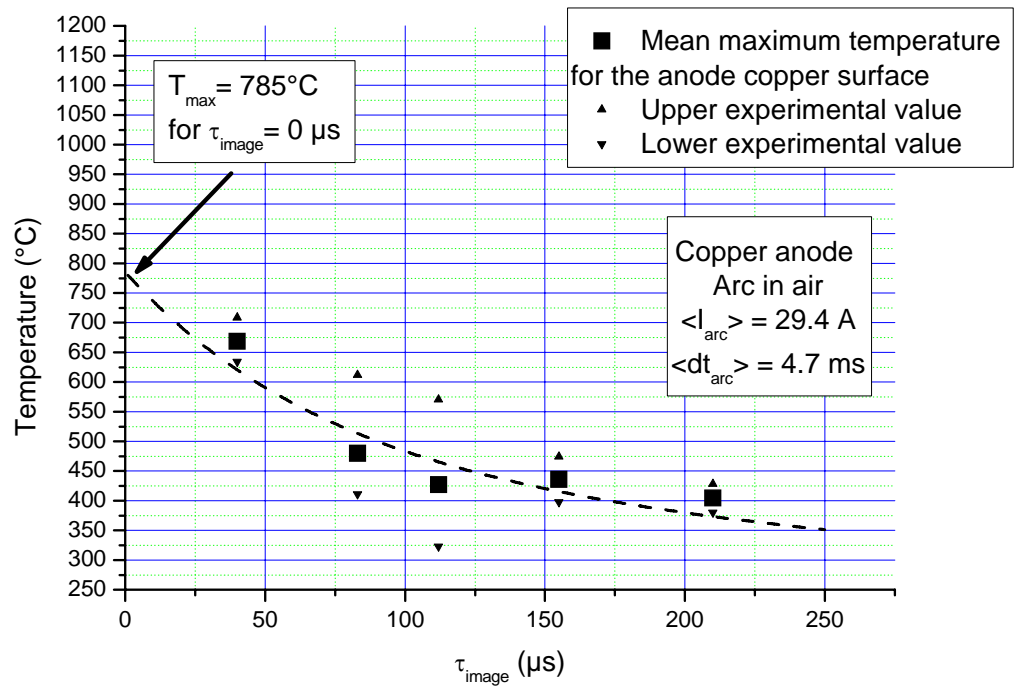

Figure 12. Evolution of the maximum surface temperature versus $\tau_{\text {image }}$ for $I_{\text {arc }} \approx 30 \mathrm{~A}$

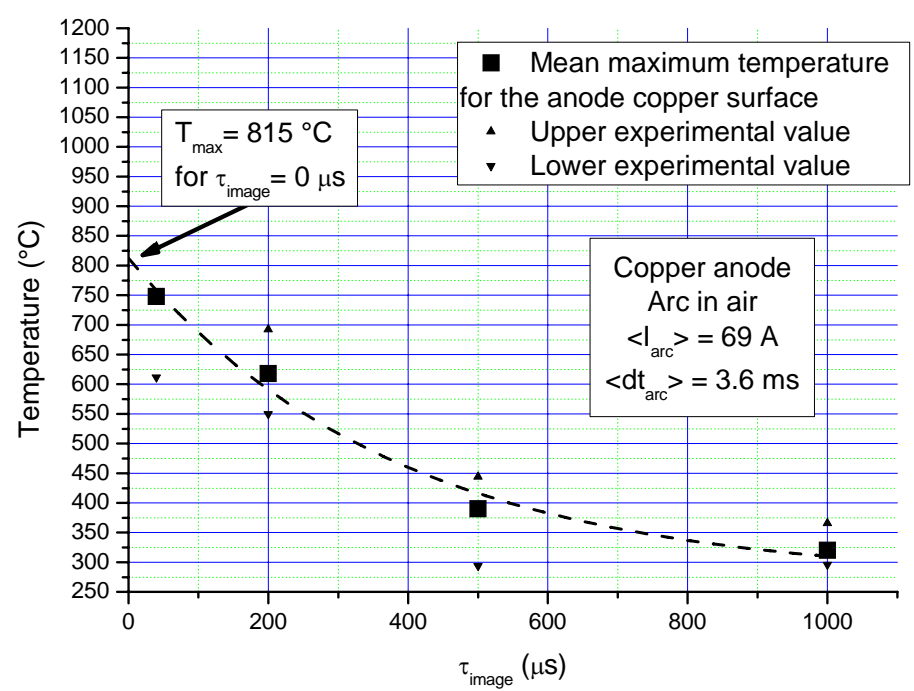

Figure 13. Evolution of the maximum surface temperature versus $\tau_{\text {image }}$ for $\mathrm{I}_{\text {arc }} \approx 70 \mathrm{~A}$ 


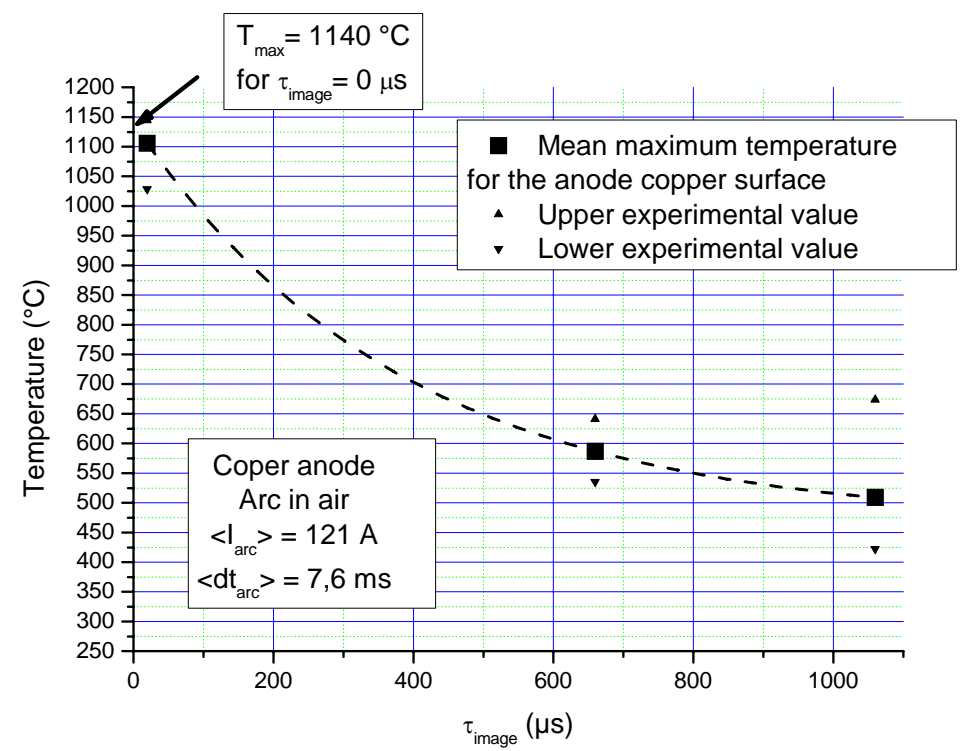

Figure 14. Evolution of the maximum surface temperature versus $\tau_{\text {image }}$ for $I_{\text {arc }} \approx 120 \mathrm{~A}$

\section{A proposition of method to assess the power balance at the anode surface thanks to the thermal measurement.}

In this part a 2D modelling of the anode heating is presented which proposes in some cases, an assessment of the power balance at the anode surface based on the temperature measurements.

\section{5-1 Description of the model for the power balance at the anode surface.}

To describe the arc-electrode interactions we do not consider the interaction between the different particles (ions, neutral species and electrons) and the electrode surface at a microscopic scale. We have adopted a macroscopic point of view for the arc root structure which corresponds to the scale of the measurements presented in the previous part. Several authors have already used a similar description, [10-14]. In these conditions the macroscopic power balance is expressed by mean of a 'volt equivalent' parameter called $V_{\text {eqA }}$.

Two simple relations are used to express the power and the surface power density received by an electrode:

$\begin{array}{ll}P_{A}=I \times V_{e q A} & (\mathrm{~W}) \\ Q_{A}=J_{A} \times V_{e q A} & \left(\mathrm{~W} / \mathrm{m}^{2}\right)\end{array}$ 
where $P_{\mathrm{A}}$ is the power brought to the anode surface, $Q_{A}$ is the surface power density brought to the anode, $I$ the arc current intensity, $V_{\text {eqA }}$ is a volt equivalent at anode, $J_{\mathrm{A}}$ is the arc current density at the anode arc root. The volt equivalent $V_{\text {eqA }}$ traduces roughly the heating due to the whole various physical phenomena contributing to the anode heating.

Moreover, the following assumptions have been made:

(i) As the numerical model used is 2D only the cases of motionless anode arc roots can be considered.

(ii) The current density at the anode surface is constant during the arc.

(iii) $V_{\text {eqA }}$ is also constant during the arc. Consequently, the surface power density is constant during the arcing process, only the area of the arc root varies with the current values.

In these conditions, several calculations have been done for several pairs $\left(J_{A}, V_{\text {eqA }}\right)$ and the calculated temperature profiles have been compared with the experimental ones, for a known arc current pulse $I$ (t). The aim was to determine the possible values for $P$ and $Q$ compatible with experimental measurements.

Even if at $\tau_{\text {image }}=40 \mu$ s the electric arc no more exists $\left(\mathrm{P}_{\mathrm{A}}=0\right.$ and $\left.\mathrm{Q}_{\mathrm{A}}=0\right)$, the surface temperature measurement at this instant may give interesting information to determine how the anode was heated during the $\operatorname{arc}\left(\right.$ when $\mathrm{P}_{\mathrm{A}} \neq 0$ and $\mathrm{Q}_{\mathrm{A}} \neq 0$ ). Indeed, the power and surface power density values during the arc also determine the temperature profile evolution after the arc extinction. It is clear that the influence of $\mathrm{P}_{\mathrm{A}}$ and $\mathrm{Q}_{\mathrm{A}}$ on the temperature profile shapes is all the more important as the $\tau_{\text {image }}$ value is small.

This method can only give an order of magnitude for $\mathrm{P}_{\mathrm{A}}$ and $\mathrm{Q}_{\mathrm{A}}$ because a uniform heating on the anode arc root was considered. It is probable that the heating at the centre of the anode arc root is more important than the heating at its edge. Moreover, different pairs $\left(\mathrm{P}_{\mathrm{A}}, \mathrm{Q}_{\mathrm{A}}\right)$ may exist, which give correct results. However, as it is shown hereafter in the paper, the different solutions that have been found give for $\mathrm{Q}_{\mathrm{A}}$ ad $\mathrm{V}_{\text {eqA }}$ values of the same order of magnitude.

Before the result presentation, the main characteristics of the numerical thermal modelling are reviewed.

\section{5-2 Brief description of the numerical modelling of the anode heating}

The numerical modelling used here has already been described in [14]. A brief recall of its main characteristics is proposed now: 
- The problem is assumed axial-symmetric and the arc root is regarded as motionless.

- The specific heat and thermal conductivity of the electrode material are taken to be temperature dependent.

- The material density is taken as constant. It has been shown in [15] that, in the case of copper, considering the temperature dependence of the material density has a small effect on the electrode heating.

- Joule heating has been neglected. In the case of a motionless arc root (i.e. a 2D case) for current density values less than $10^{11} \mathrm{Am}^{-2}$ this assumption is valid [16] for a flat electrode.

- The motions induced in the molten part of the electrode by Lorentz forces, Marangoni effects or plasma jets/electrode surface interactions are neglected.

The boundary conditions for the simple electrode geometry are shown in figure 15 and given as follows:

- The heat flux on the upper surface of the electrode is given by the power $P(t)$ and the surface power density $Q$.

- The heat flux on the lateral sides of the electrode has been neglected. This assumption is valid because only short duration arcs are considered.

- The bottom temperature is fixed to $T=T_{0}$ (equal to $25^{\circ} \mathrm{C}$ ) on the lower cross section of the electrode.

The following equations have then to be solved:

- The heat diffusion equation in the non-stationary regime in each phase (solid and liquid) takes the following form:

$$
\rho C_{p} \frac{\partial T}{\partial t}=\operatorname{div}(k(T) \vec{\nabla} T)+S
$$

where $\rho$ is the material density, $C_{p}$ the specific heat, $T$ the temperature, $t$ the time, $k$ the thermal conductivity, $S$ may represent some power density sources (Joule effect, etc). The last term $S$ is neglected here.

- The equation at the boundary between each phase (denoted 1 and 2) has the following form:

$$
[k \vec{\nabla} T]_{1}^{2}=-\rho L_{1 \rightarrow 2} v_{s}
$$

where $v_{\mathrm{s}}$ is the velocity of the boundary between two phases and $L_{1 \rightarrow 2}$ is the latent heat of the change of state (state 1 to state 2). This condition is called the 'Stefan condition'. Several numerical methods are proposed to simulate the melting front's evolution $[17,18]$ by tracking the melting front. The difficulty of the 'Stefan problem' lies in the discontinuity of the enthalpy function H(T). The method used overcomes this difficulty by making the enthalpy function continuous. The phase is considered to 
occur continuously over a temperature interval $\left[T_{\mathrm{c}}-\varepsilon ; T_{\mathrm{c}}+\varepsilon\right]$, where $T_{\mathrm{c}}$ is usually the melting or the vaporization temperature. This method is equivalent to creating a fictitious specific heat equal to $L / 2 \varepsilon$. Here $\varepsilon$ was taken to be equal to $10^{\circ} \mathrm{C}$. Only equation (4) has then to be solved. Concerning the problem relative to the free moving vapour front, the method used is described in [19]. The discretization of the heat equation is based on a finite difference numerical method with an implicit time scheme.

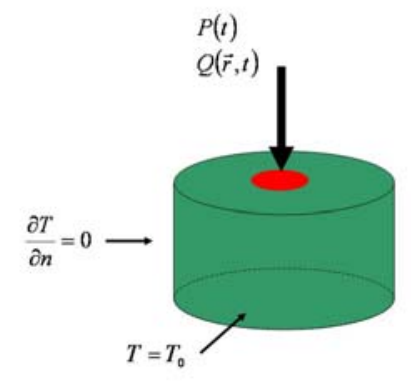

Figure 15. Schematic description of the geometry and of the boundary conditions of the numerical modelling.

\section{5-3 Example of results and discussion.}

As mentioned above, only case of static or quasi-motionless arc may be used for the calculations. In figure 16 two temperature profiles obtained for $\tau_{\text {image }}=40 \mu$ s have been plotted for the following experimental conditions:

Case $n^{\circ} 1$ :

- $\quad \mathrm{I}_{\mathrm{arc}}=131 \mathrm{~A}$

- $\quad$ Arc duration $=8.7 \mathrm{~ms}$

Case $n^{\circ} 2$ :

- $\quad \mathrm{I}_{\mathrm{arc}}=67 \mathrm{~A}$

- $\quad$ Arc duration $=3.8 \mathrm{~ms}$ 


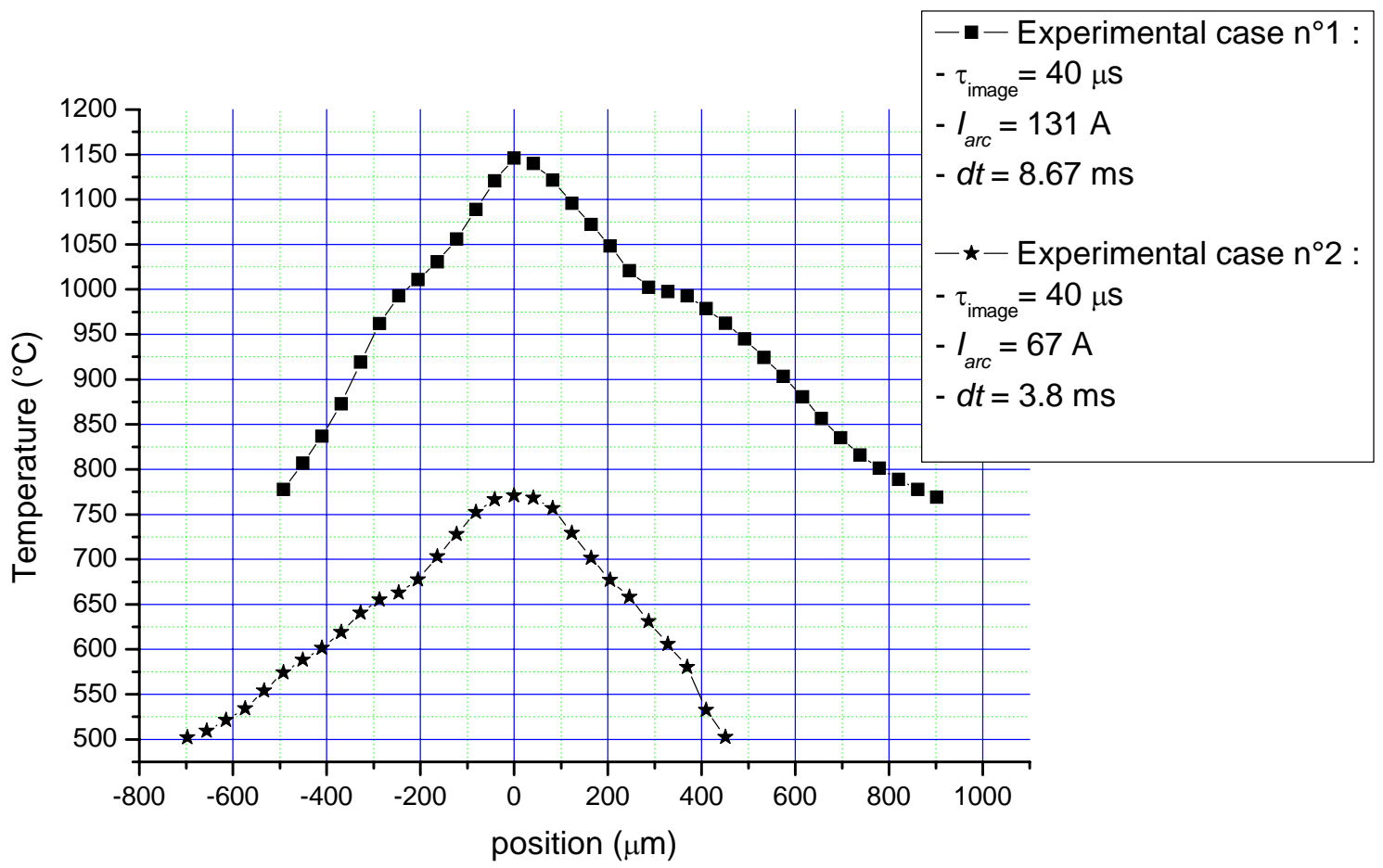

Figure 16. Two examples of temperature profiles.

In figures 17 and 18 different calculated surface temperature profiles have been plotted for several values of $\mathrm{V}_{\text {eqA }}$ and $\mathrm{Q}_{\mathrm{A}}$. In the two cases three surface temperature profiles obtained for three pairs $\left(\mathrm{V}_{\text {eqA }}, \mathrm{Q}_{\mathrm{A}}\right)$ have been plotted. The $\mathrm{V}_{\text {eqA }}$ and $\mathrm{Q}_{\mathrm{A}}$ values have been chosen in order to obtain temperature profiles "close" to the experimental profiles, that is to say:

- a maximum calculated temperature equal to the maximum experimental temperature to within $75^{\circ} \mathrm{C}$.

- a spatial extension of the calculated profiles close to the experimental one However, some differences appeared. For instance, the experimental temperature profiles were not symmetric. That may be due to the fact that the anode arc root was not truly motionless which may have been difficult to detect with the high speed camera. Then the experimental profiles were wider than the calculated ones for $r>350 \mu \mathrm{m}$ for the case $\mathrm{n}^{\circ} 1$ on the right side of the experimental profile and for $r>300 \mu \mathrm{m}$ on the left side for the case $n^{\circ} 2$. Moreover, the spatial surface power density distribution used for the calculations was considered uniform on a disc of radius $I_{a r c} / J_{a}$. This rough approximation, allowing to obtain an order of magnitude of the surface power density mean value, did certainly not correspond to the reality. It is also important to note that the "best fit" was made in the two cases for similar values of $\mathrm{V}_{\text {eqA }} \approx 12 \mathrm{~V}$ and $\mathrm{Q}_{\mathrm{A}} \approx 1.8 \times 10^{9} \mathrm{~W} / \mathrm{m}^{2}$ even if the current intensities and arc duration were quite different. 
With the present method, the $\mathrm{V}_{\mathrm{EqA}}$ and $\mathrm{Q}_{\mathrm{A}}$ values obtained seem to be in good agreement with experimental studies $[11,14,20,21]$. The difference with the modelling works may be due to the difference of scale considered: The aim was to obtain order of magnitude for the surface power density so no microscopic phenomena such as microscopic spots were taken into account.

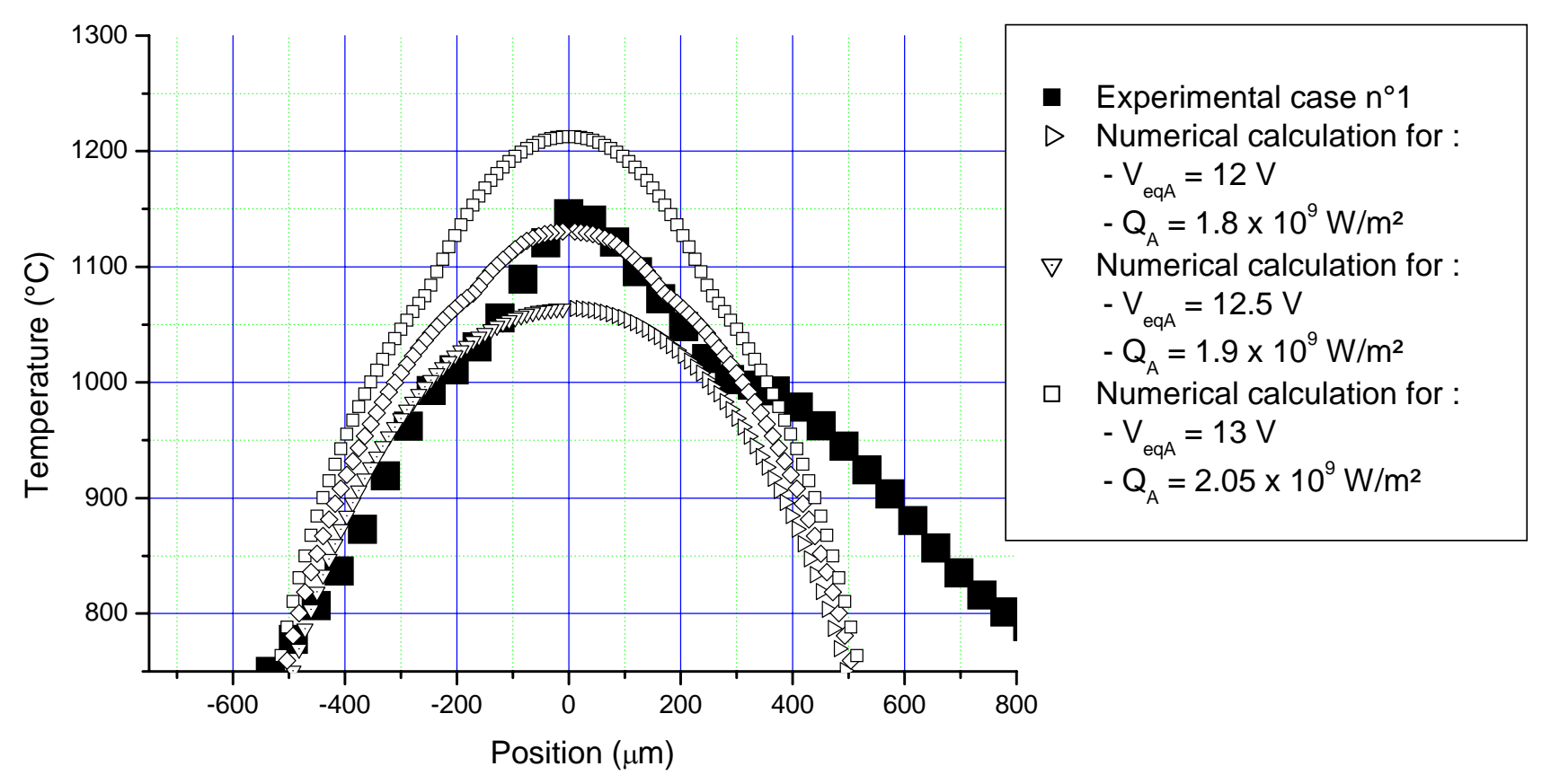

Figure 17. Experimental temperature profile in the case $\mathrm{n}^{\circ} 1$ and three numerical results for three pairs $\left(\mathrm{V}_{\mathrm{eqA}}, \mathrm{Q}_{\mathrm{A}}\right)$ 


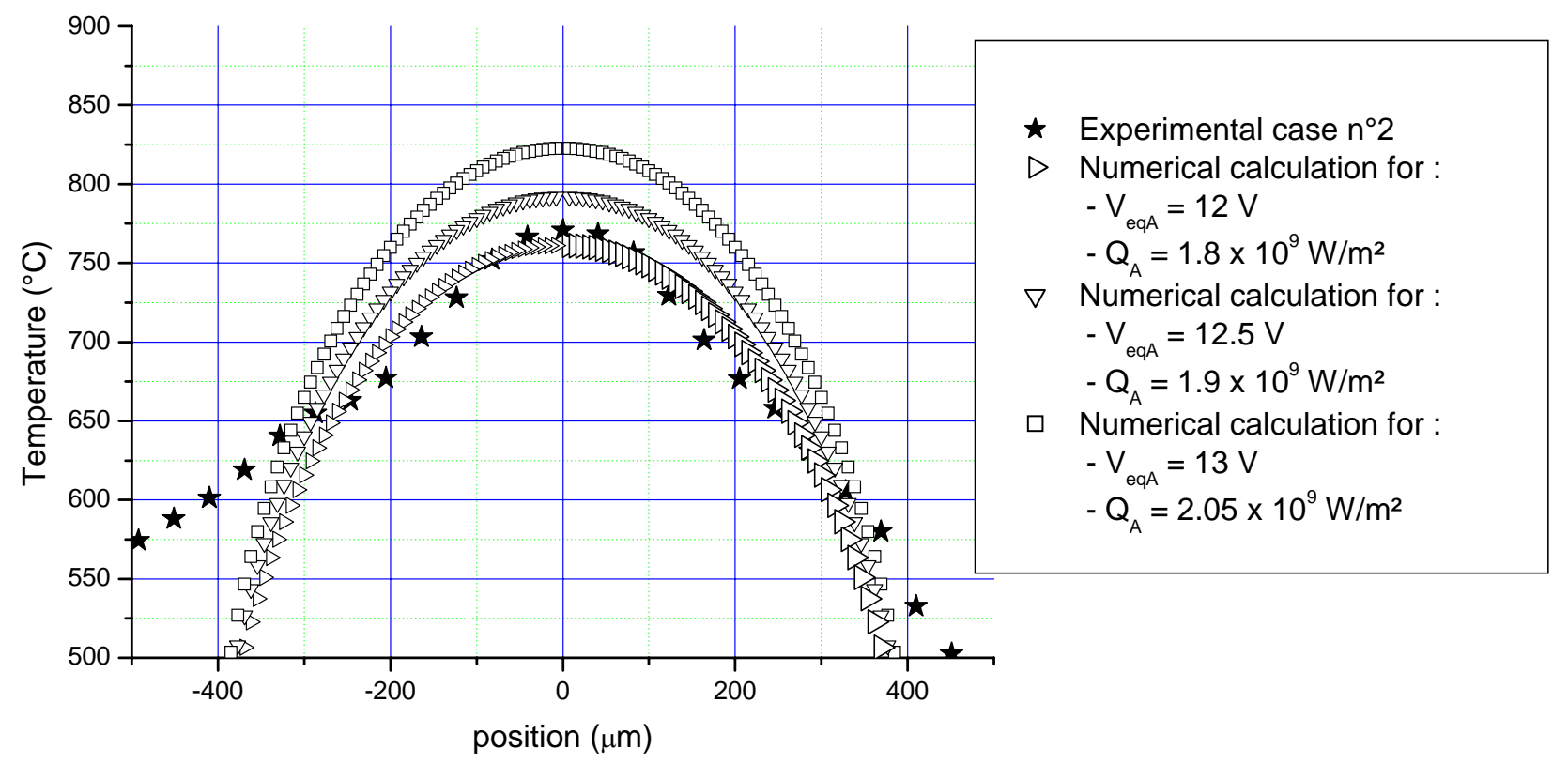

Figure 18. Experimental temperature profile in the case $n^{\circ} 2$ and three numerical results for three pairs $\left(\mathrm{V}_{\mathrm{eqA}}, \mathrm{Q}_{\mathrm{A}}\right)$

Other works have proposed values for $\mathrm{V}_{\text {eqA }}$ and $\mathrm{Q}$ :

- In [20], for an arc current intensity of $30 \mathrm{~A}, \mathrm{~V}_{\mathrm{eqA}}$ was found in the range of $6.9 \mathrm{~V}-13 \mathrm{~V}$ according to the electrode gap value.

- $\quad$ In [21] $\mathrm{Q}_{\mathrm{A}}$ has been found in the range of $5 \times 10^{8}-10^{10} \mathrm{~W} / \mathrm{m}^{2}$ and $6.25 \mathrm{~V}<\mathrm{V}_{\mathrm{eqA}}<20 \mathrm{~V}$.

- $\quad$ In [12] $\mathrm{V}_{\text {eqA }}$ was found equal to equal to $11 \mathrm{~V}$ and the surface power density in the range of $3 \times 10^{9} \mathrm{~W} / \mathrm{m}^{2}-2 \times 10^{10} \mathrm{~W} / \mathrm{m}^{2}$

- In [11] for an arc duration of $5 \mathrm{~ms}$ and an electrode gap of $5 \mathrm{~mm}, 6 \mathrm{~V}$ seems to be a good value for $\mathrm{V}_{\text {eqA }}$ for a current intensity in the range of 200A- 600A and $\mathrm{Q}_{\mathrm{A}}$ was found equal to $1.210^{9} \mathrm{~W} / \mathrm{m}^{2}$.

- In [14] it was found that for short duration arc (some hundreds microseconds), $V_{\text {eqA }}$ was in the range of 9-12.6V and $\mathrm{Q}_{\mathrm{A}}$ about $6 \times 10^{9} \mathrm{~W} / \mathrm{m}^{2}$.

Modelling works are most of the time made at a microscopic scale. In [10] $\mathrm{V}_{\mathrm{eqA}}$ was found in the range of 8.7-9.6V and $\mathrm{Q}_{\mathrm{A}}$ in the range of $2.15 \times 10^{11}-4.3 \times 10^{11} \mathrm{~W} / \mathrm{m}^{2}$. 


\section{Conclusions}

The aim of this paper was to obtain information concerning the maximum surface temperature and the temperature distribution reached on copper anodes submitted to a non stationary electric arc burning in air at atmospheric pressure. For that the temperature distribution on the electrode surface was measured with the help of an IR camera.

The experimental method brought into operation presents several advantages:

- The IR camera may be used with short exposure times (between $10 \mu \mathrm{s}$ and $120 \mu \mathrm{s}$ ).

- The pixel size of the camera may be small $(40 \mu \mathrm{m} \times 60 \mu \mathrm{m})$.

- The duration of the switching off of the electric arc is forced and brutal (more than $200 \mathrm{~A} / \mu \mathrm{s})$.

- The IR camera may be precisely synchronized.

For such experimental conditions (non stationary arc in air, copper anodes, ...) it was then possible to obtain for the first time a temperature map of the electrode surface for different delays (from $40 \mu$ s to $1 \mathrm{~ms}$ ) after the arc extinction.

Different heating mode have been observed resulting from different behaviors of the anode arc root based on that it was not moving, moving by jumps or continuously moving.

The measurement of the temperature distribution for different delays allowed also to propose, by extrapolation, an assessment of the temperature at the arc extinction instant. Maximum average temperatures was found in the range of $780{ }^{\circ} \mathrm{C}-1150{ }^{\circ} \mathrm{C}$ for $\mathrm{I}_{\text {arc }}$ in the range of $30 \mathrm{~A}-130 \mathrm{~A}$ and arc duration in the range of 2-5 ms.

The use of a simple 2D numerical modeling of the anode heating allowed to evaluate the power balance at the surface in the case of a motionless anode arc root. The values for the volt equivalent are found about $12 \mathrm{~V}$ and the values for the surface power density are found to be near $2 \times 10^{9} \mathrm{~W} / \mathrm{m}^{2}$. 


\section{References}

[1] J. Haidar and J D Farmer, J. Phys. D: Appl. Phys., 26, pp. 1224-1229, (1993)

[2] J. Haidar and J D Farmer, J. Phys. D: Appl. Phys,. 28, pp. 2089-2094, (1995)

[3] X Zhou, B. Ding and J. Heberlein, in Proceedings of the $41^{\text {th }}$ Holm Conference, Montreal, 1995, pp. 219-231

[4] L. Dabringhausen, D. Nandelstädt, J. Luhmann and J. Mentel, J. Phys. D: Appl. Phys., 35, pp. 1621-1630, (2002)

[5] J. Peters, F. Yin, C. F M Borges, J. Heberlein and C. Hackett, J. Phys. D: Appl. Phys,. 38, pp. 1781-1794, (2005)

[6] E. Dullni, B. Gellert, E. Schade, IEEE Transactions on Plasma Science, 17, n5, pp. 644-648, (1989)

[7] Ph. Teste, R. Andlauer and T. Leblanc, IET Science Measurement and Technology, 4, n³, pp. 156$168,(2010)$

[8] T. Klonowski, Ph.D. thesis, University Paris XI, 2007

[9] Y.Zhu, K.Mimura, J-W Lim, M. Isshiki and Q. Jiang Metallurgical and Materials Transactions, 37, pp. 1231-1237, (2006)

[10] H. Salihou, M. Abbaoui, A. Lefort and R. Auby, J. Phys. D: Appl. Phys,. 28, pp. 1883-1887, (1995)

[11] J. Devautour, J.-P. Chabrerie and Ph. Teste Ph., J. Phys. III, 3, 1157-1166, 1993

[12] A. Marotta, L. I. Sharakhovsky and V. Borisyuk, J. Phys.D: Appl. Phys., 30, pp. 2018-25, 1997

[13] N. A. Sanders and E. Pfender, J. Appl. Phys. 55, pp. 714-22, 1984

[14] Ph. Teste, T. Leblanc, J. Rossignol, R. Andlauer, Plasma Sources Science and Technology, 17, (2008)

[15] L. W. Hunter and J. R Kutler, J. Heat Trans. ASME, 239, (1989)

[16] Z. J. He and R. Haug, J. Phys. D: Appl. Phys., 26, pp. 603-13, (1997)

[17] R. Gupta and A. Kumar, Computer Methods in Applied Mechanics and Engineering, 56, pp.127$138,(1986)$

[18] N. Morita, J. Appl. Phys., 56, pp.1987-1991, (1984)

[19] Ph. Teste, Ph.D. thesis, University of Paris VI, 1994

[20] W. Rieder, Z. Phys., 146, pp. 629-43, (1956)

[21] J. D. Cobine and E. E. Burger, J. Appl. Phys., 26, pp. 895-900, (1955) 


\section{List of figure captions :}

Figure 1. Schematic description of the electrical part of the experimental device

Figure 2. Schematic description of the experimental device.

Figure 3. Photography of the electrodes before the arc: the contact is closed.

Figure 4. Description of the different delays for $\tau_{\text {exposure }}=50 \mu \mathrm{s}$ and $\tau_{\text {image }}=40 \mu \mathrm{s}$.

Figure 5. Typical time evolution of arc voltage and arc current.

Figure 6. Example of a macroscopic crater and of a multitude of microscopic craters due to very localized heating

Figure 7(a). Example of surface temperature distribution in the case of a jumping arc

Figure 7(b). Example of surface topology after a jumping arc

Figure 8. Example of surface temperature distribution in the case of a motionless arc.

Figure 9(a). Example of surface temperature distribution in the case of an arc in continuous motion.

Figure 9(b). Example of surface topology after an arc in continuous motion (fig.9(a)).

Figure 10. Two temperature profiles for two arc current intensities: $I_{\text {arc }}=43 \mathrm{~A}$ and $131 \mathrm{~A}$

Figure 11. Examples of different surface temperature profiles measured along the diameter of the arc root for $\tau_{\text {image }}=40 \mu \mathrm{s}, 200 \mu \mathrm{s}, 500 \mu \mathrm{s}, 1000 \mu \mathrm{s}$

Figure 12. Evolution of the maximum surface temperature versus $\tau_{\text {image }}$ for $\mathrm{I}_{\text {arc }} \approx 30 \mathrm{~A}$

Figure 13. Evolution of the maximum surface temperature versus $\tau_{\text {image }}$ for $\mathrm{I}_{\text {arc }} \approx 70 \mathrm{~A}$

Figure 14. Evolution of the maximum surface temperature versus $\tau_{\text {image }}$ for $I_{\text {arc }} \approx 120 \mathrm{~A}$

Figure 15. Schematic description of the geometry and of the boundary conditions of the numerical modelling.

Figure 16. Two examples of temperature profiles.

Figure 17. Experimental temperature profile in the case $\mathrm{n}^{\circ} 1$

and three numerical results for three pairs $\left(\mathrm{V}_{\mathrm{eqA}}, \mathrm{Q}_{\mathrm{A}}\right)$

Figure 18. Experimental temperature profile in the case $n^{\circ} 2$

and three numerical results for three pairs $\left(\mathrm{V}_{\mathrm{eqA}}, \mathrm{Q}_{\mathrm{A}}\right)$ 


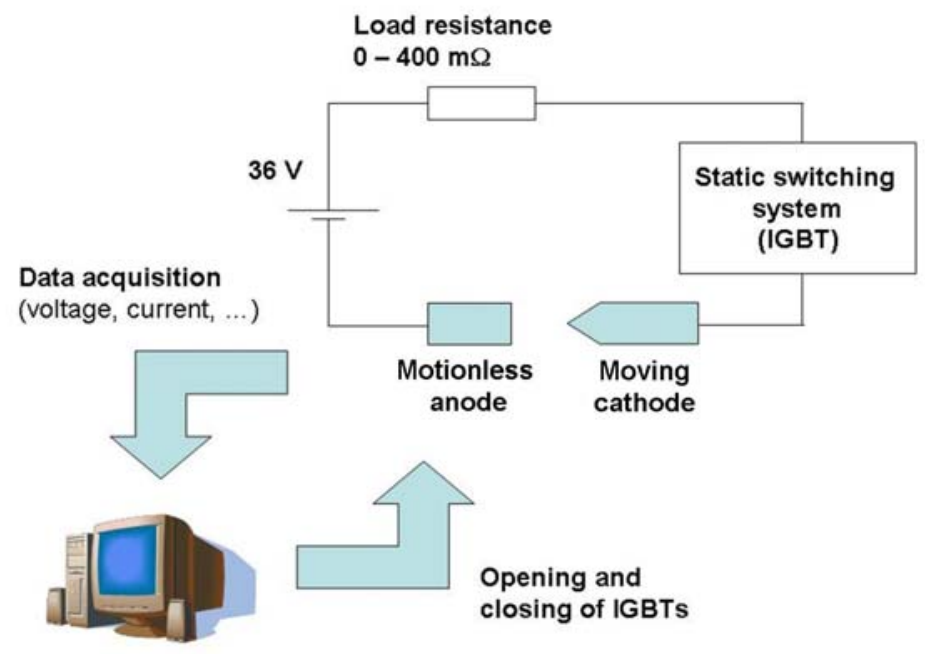

\section{Electrical device}

Figure 1. Schematic description of the electrical part of the experimental device

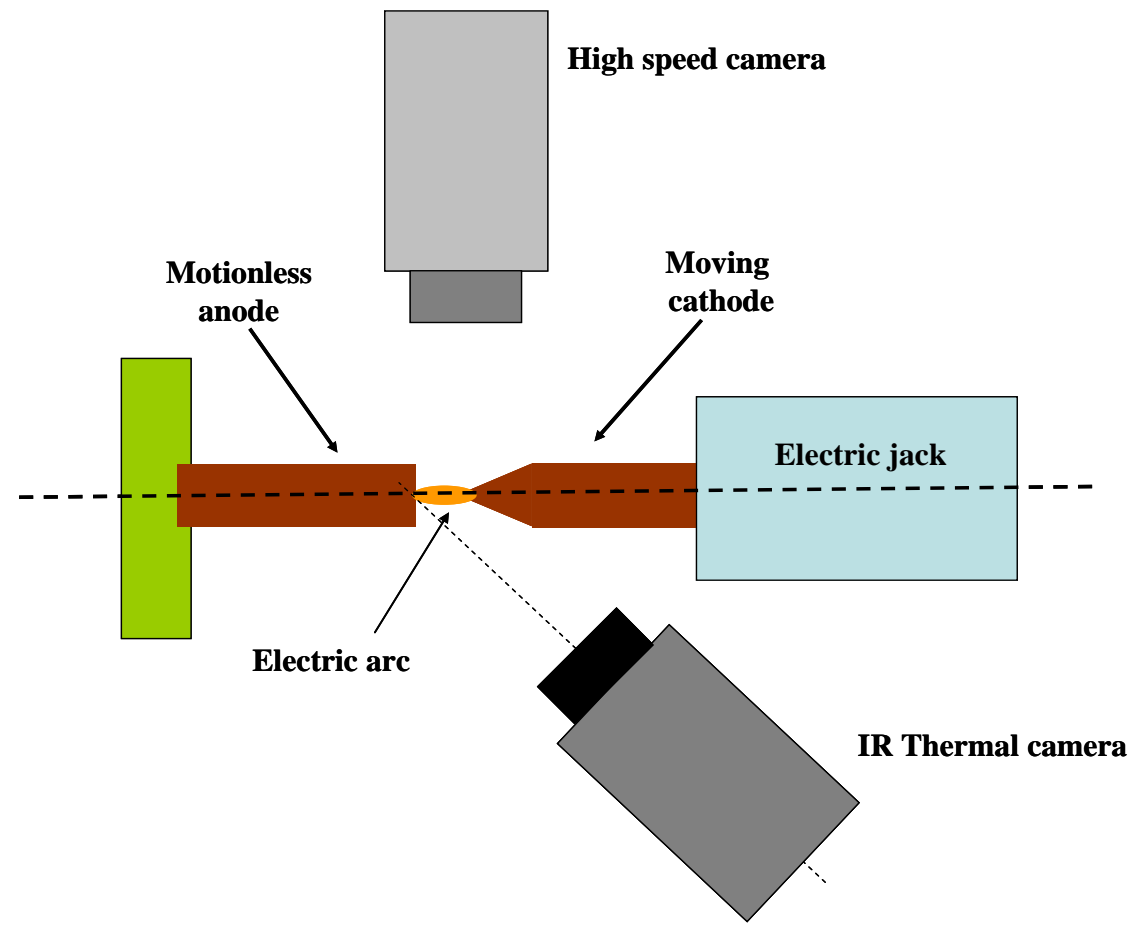

Figure 2. Schematic description of the experimental device. 


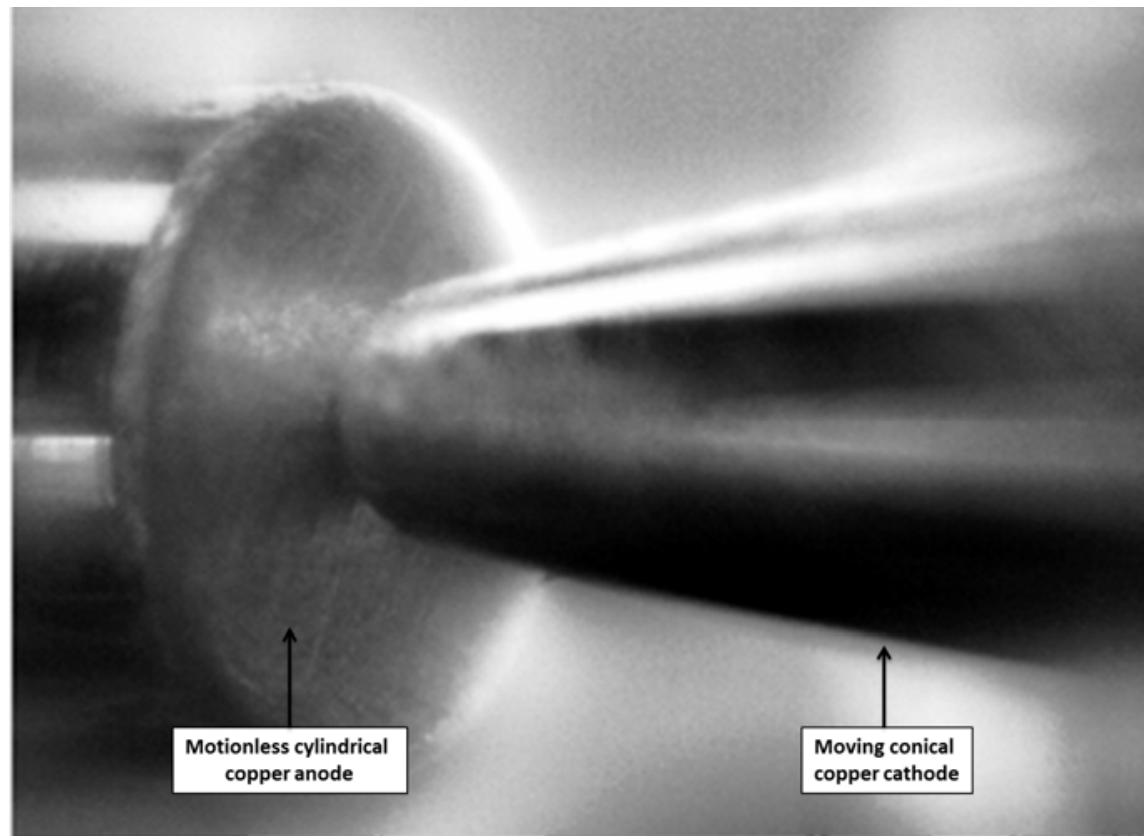

Figure 3. Photography of the electrodes before the arc: the contact is closed.

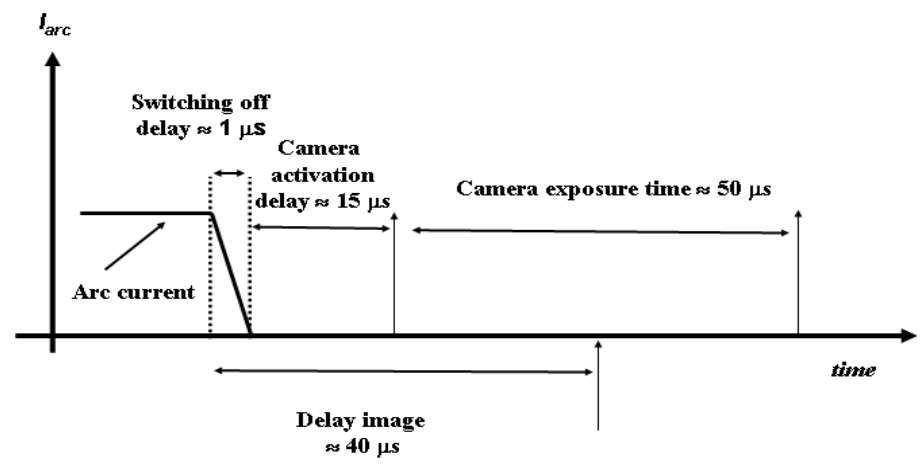

Figure 4. Description of the different delays for $\tau_{\text {exposure }}=50 \mu \mathrm{s}$ and $\tau_{\text {image }}=40 \mu \mathrm{s}$. 


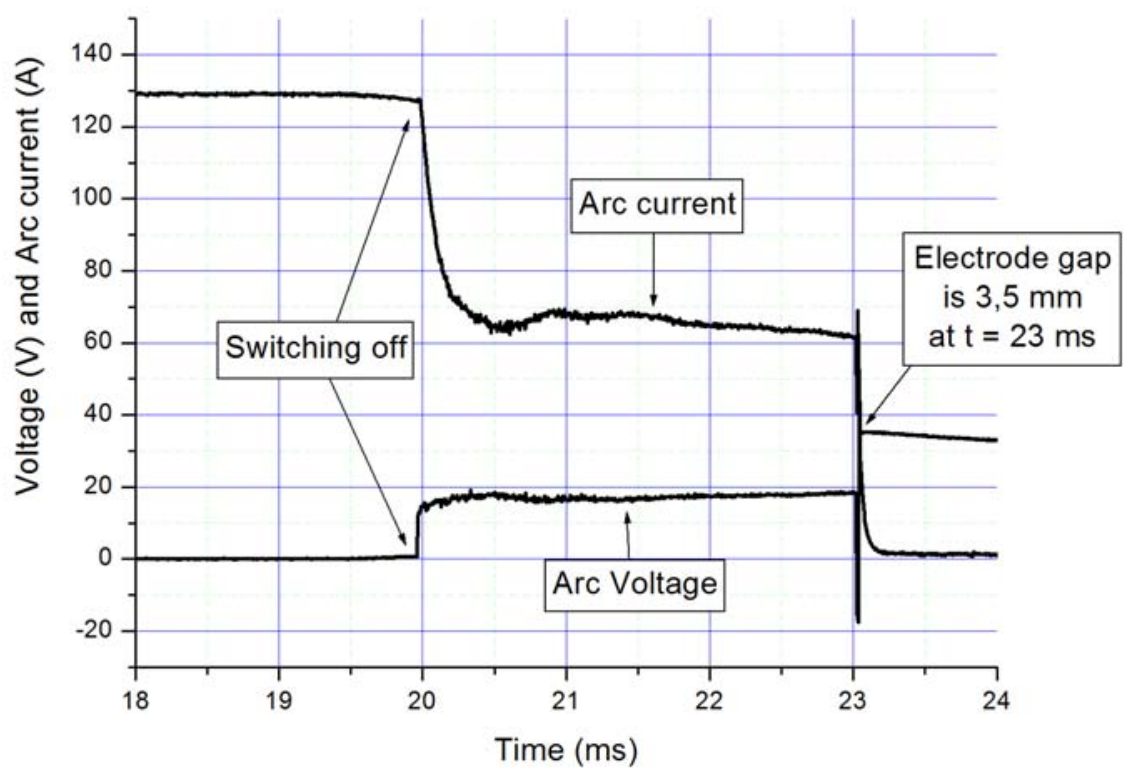

Figure 5. Typical time evolution of arc voltage and arc current.

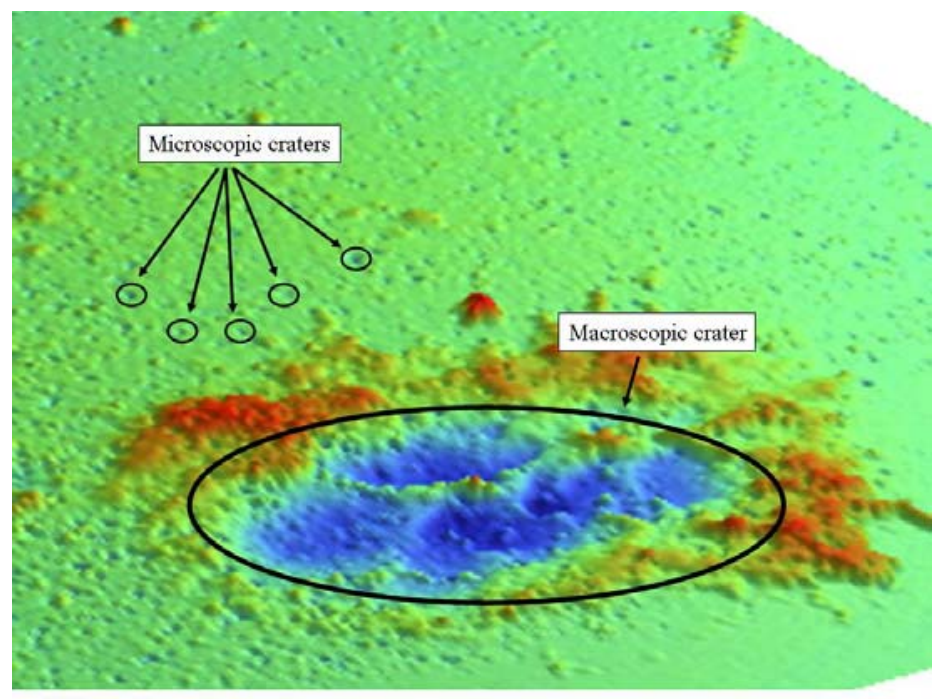

Figure 6. Example of a macroscopic crater and of a multitude of microscopic craters due to very localized heating. 


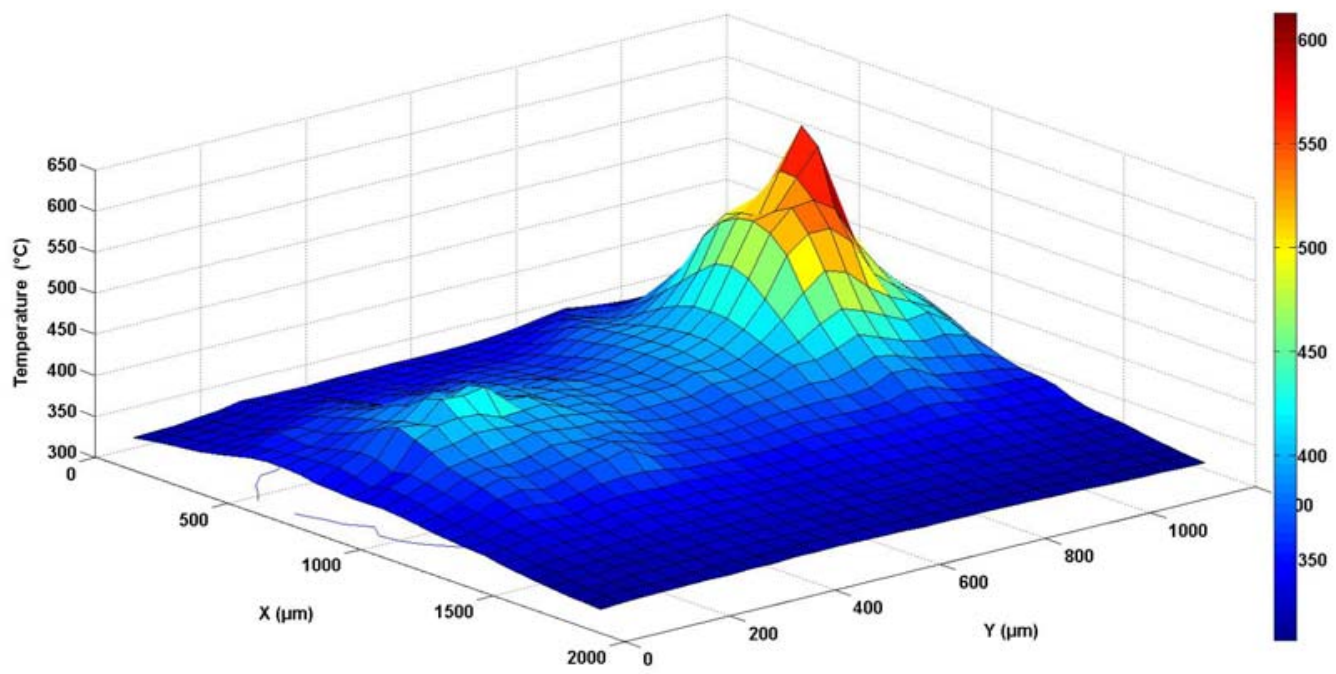

Figure 7(a). Example of surface temperature distribution in the case of a jumping arc.

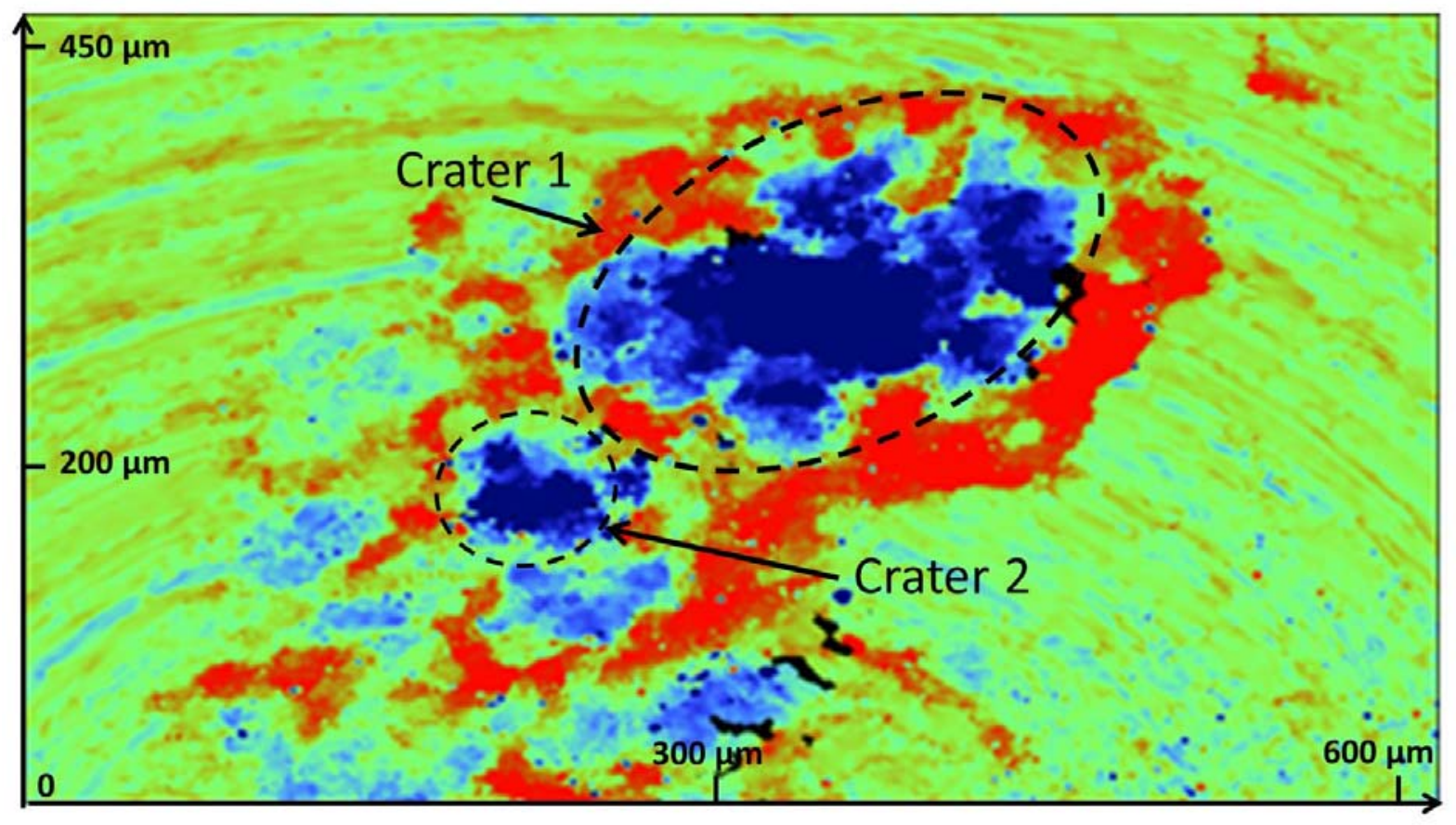

Figure 7(b). Example of surface topology after a jumping arc 


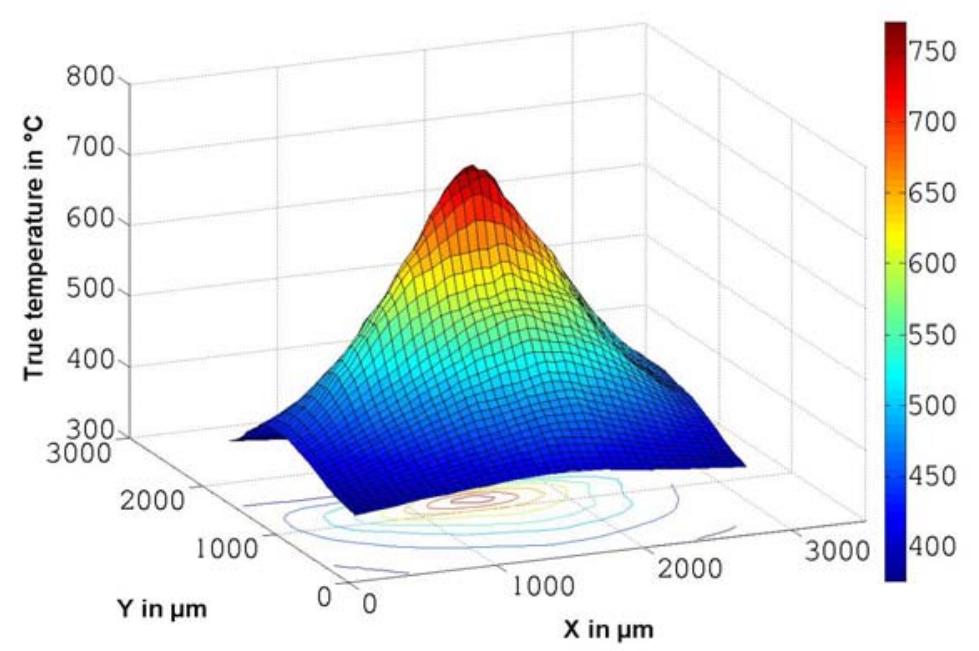

Figure 8. Example of surface temperature distribution in the case of a motionless arc.

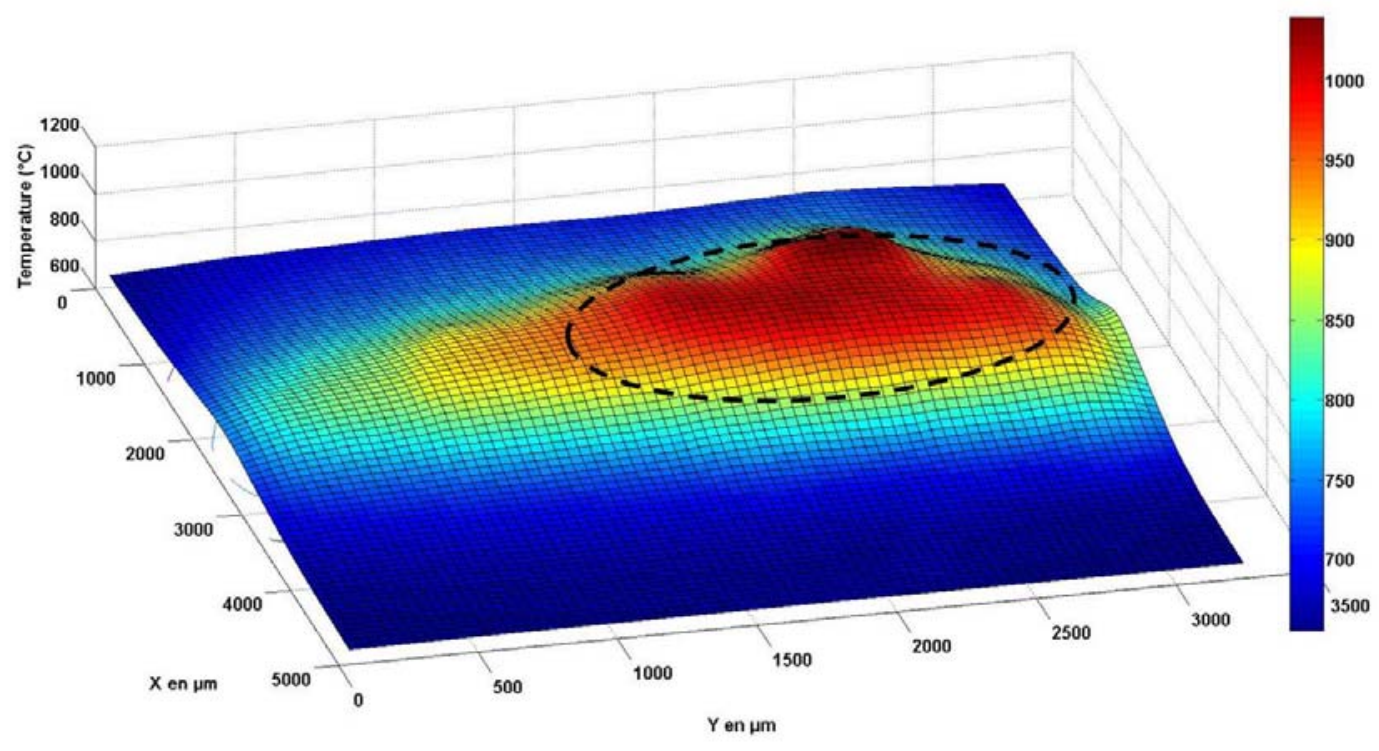

Figure 9(a). Example of surface temperature distribution in the case of an arc in continuous motion. 


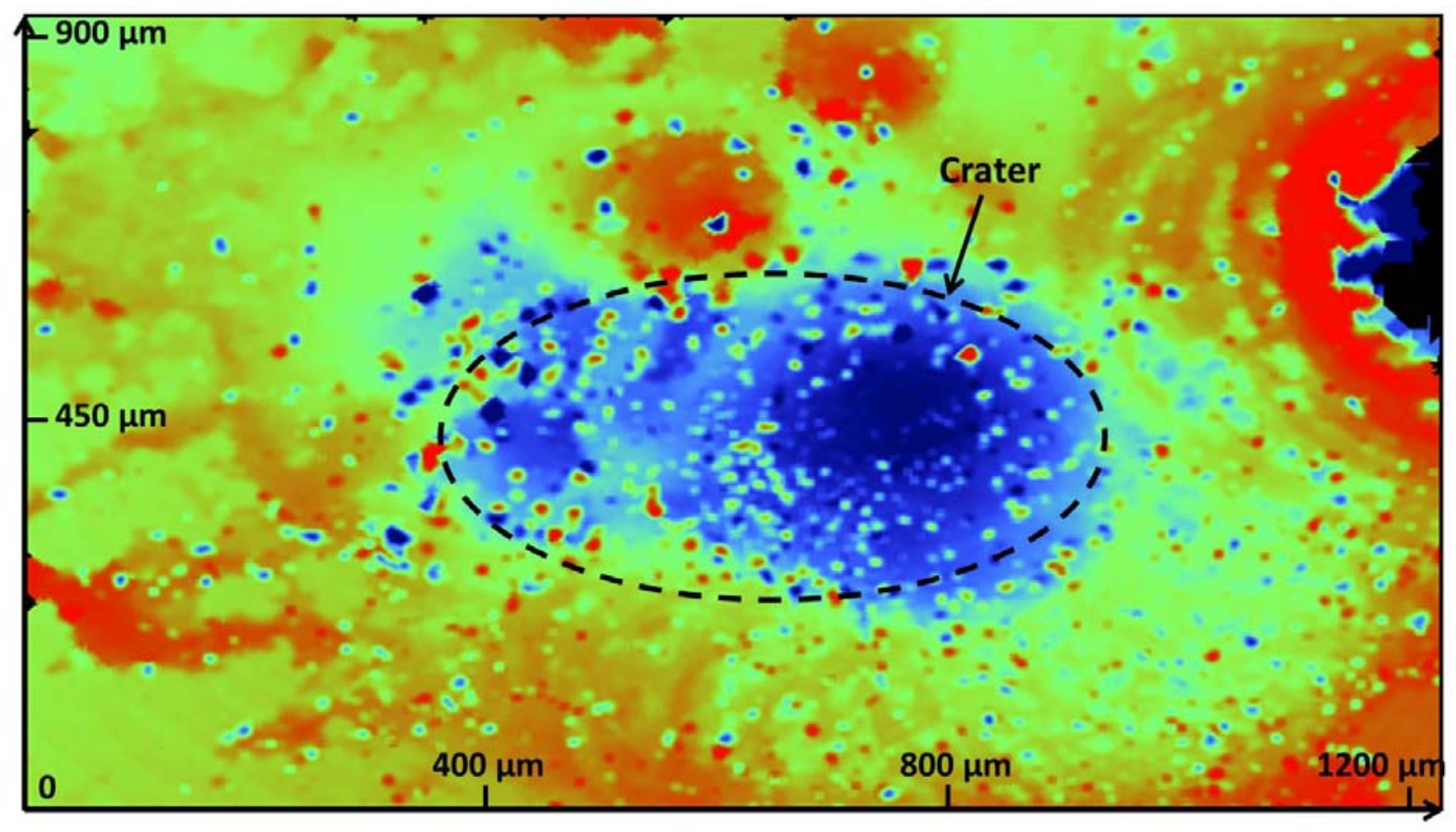

Figure 9(b). Example of surface topology after an arc in continuous motion (fig.9(a)).

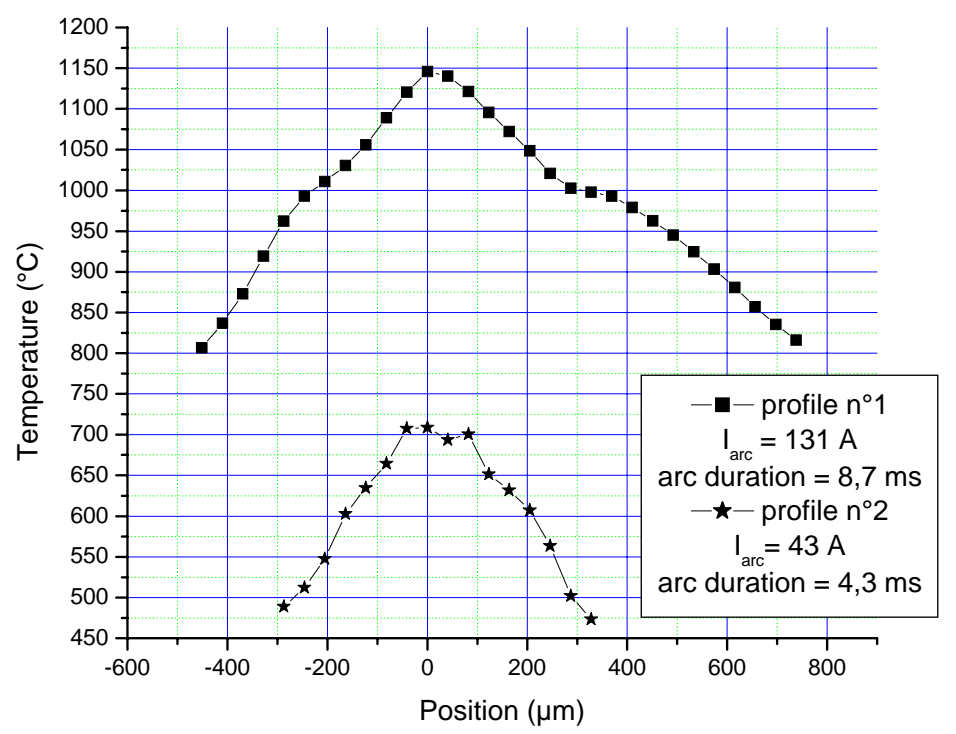

Figure 10. Two temperature profiles for two arc current intensities: $I_{\text {arc }}=43 \mathrm{~A}$ and $131 \mathrm{~A}$. 


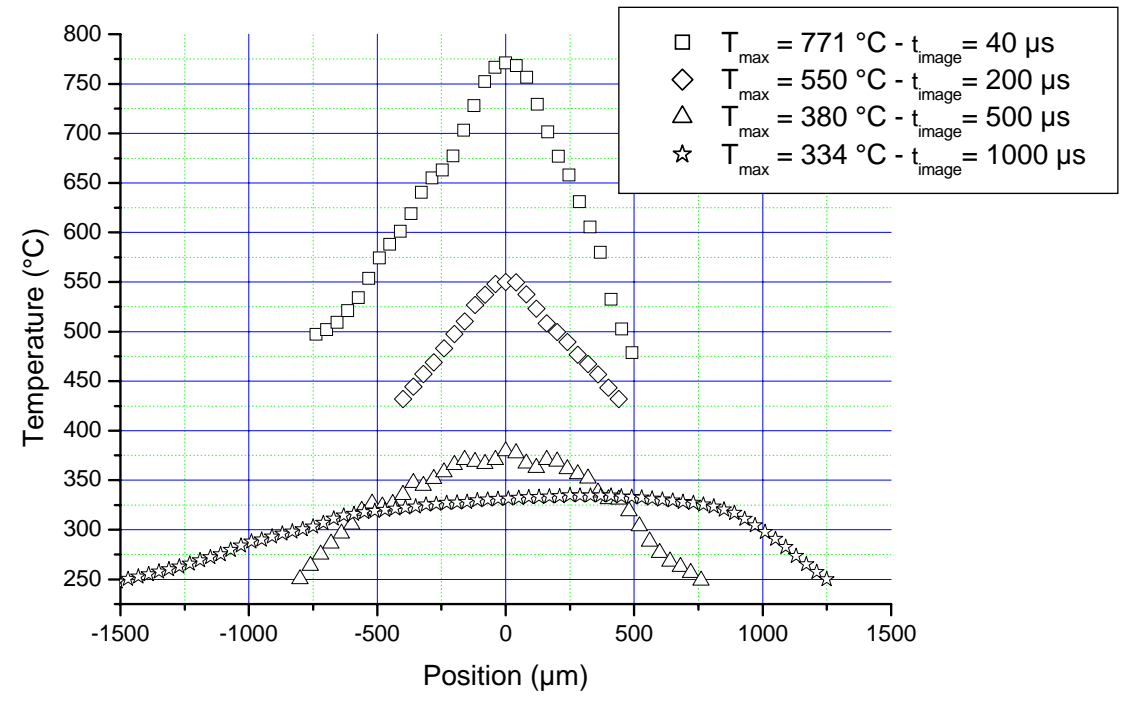

Figure 11. Examples of different surface temperature profiles measured along the diameter of the arc root for $\tau_{\text {image }}=40 \mu \mathrm{s}, 200 \mu \mathrm{s}, 500 \mu \mathrm{s}, 1000 \mu \mathrm{s}$

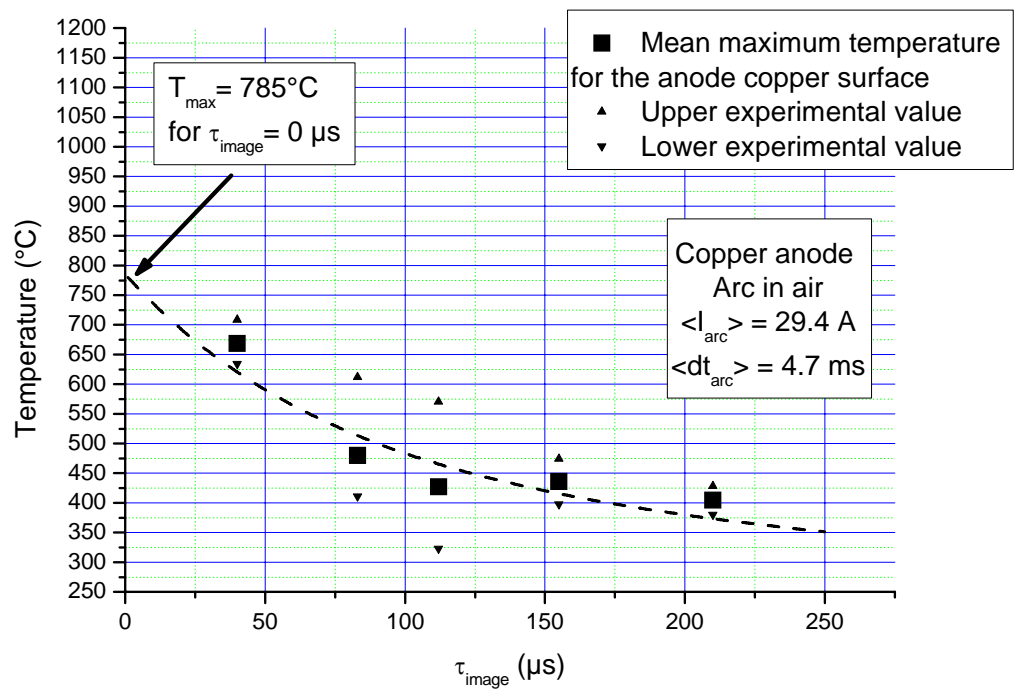

Figure 12. Evolution of the maximum surface temperature versus $\tau_{\text {image }}$ for $\mathrm{I}_{\text {arc }} \approx 30 \mathrm{~A}$ 


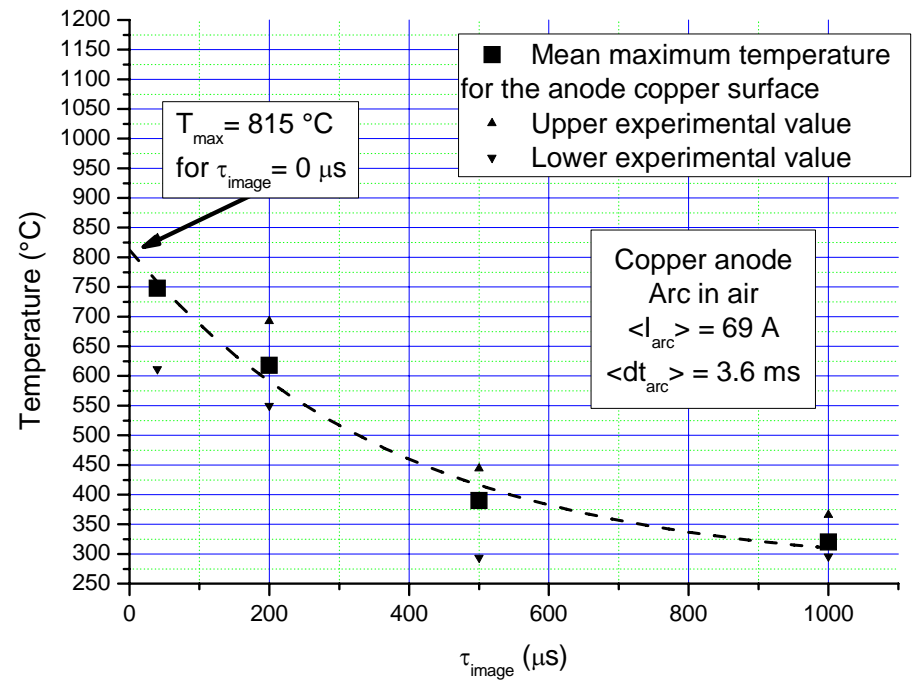

Figure 13. Evolution of the maximum surface temperature versus $\tau_{\text {image }}$ for $\mathrm{I}_{\mathrm{arc}} \approx 70 \mathrm{~A}$

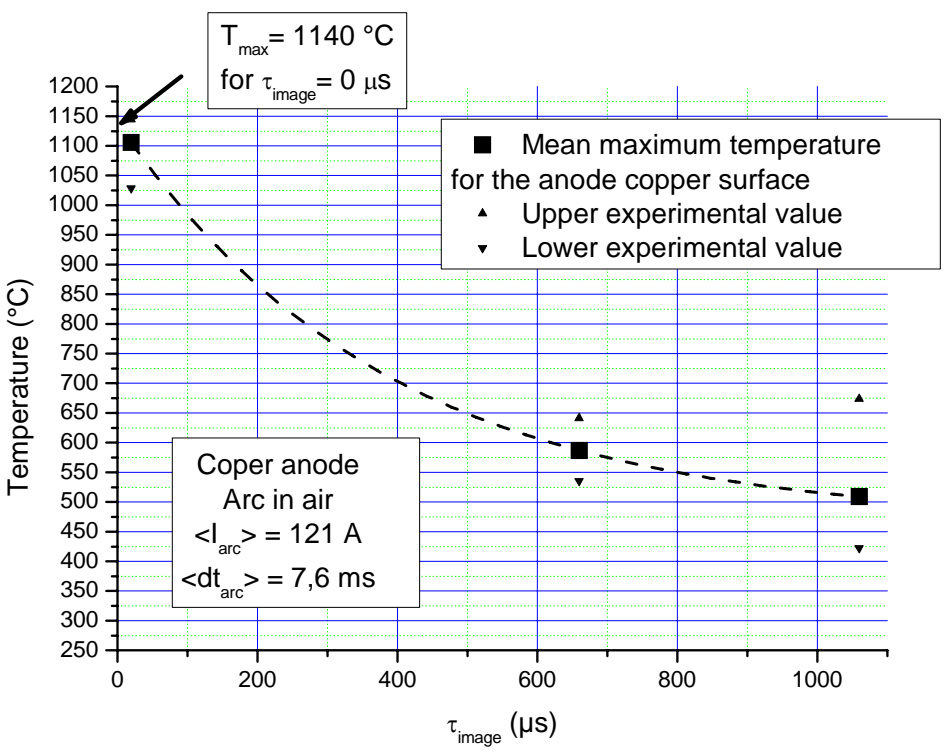

Figure 14. Evolution of the maximum surface temperature versus $\tau_{\text {image }}$ for $\mathrm{I}_{\text {arc }} \approx 120 \mathrm{~A}$ 


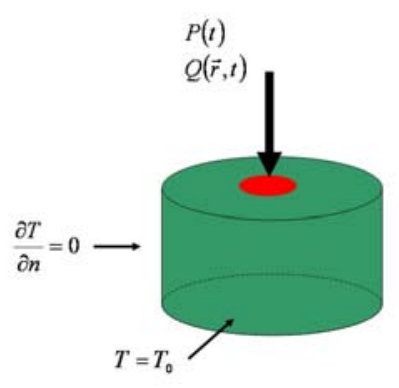

Figure 15. Schematic description of the geometry and of the boundary conditions of the numerical modelling.

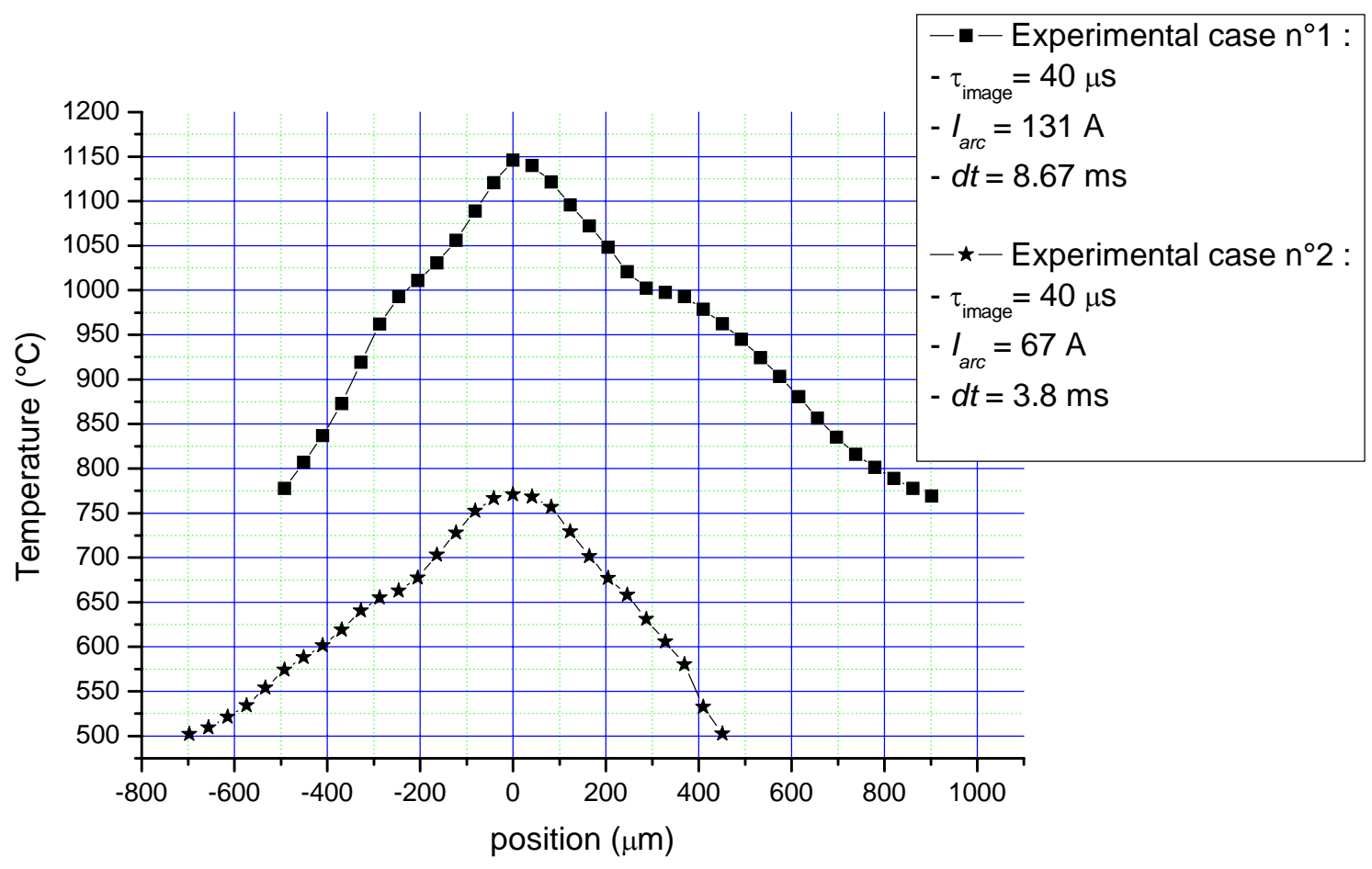

Figure 16. Two examples of temperature profiles. 


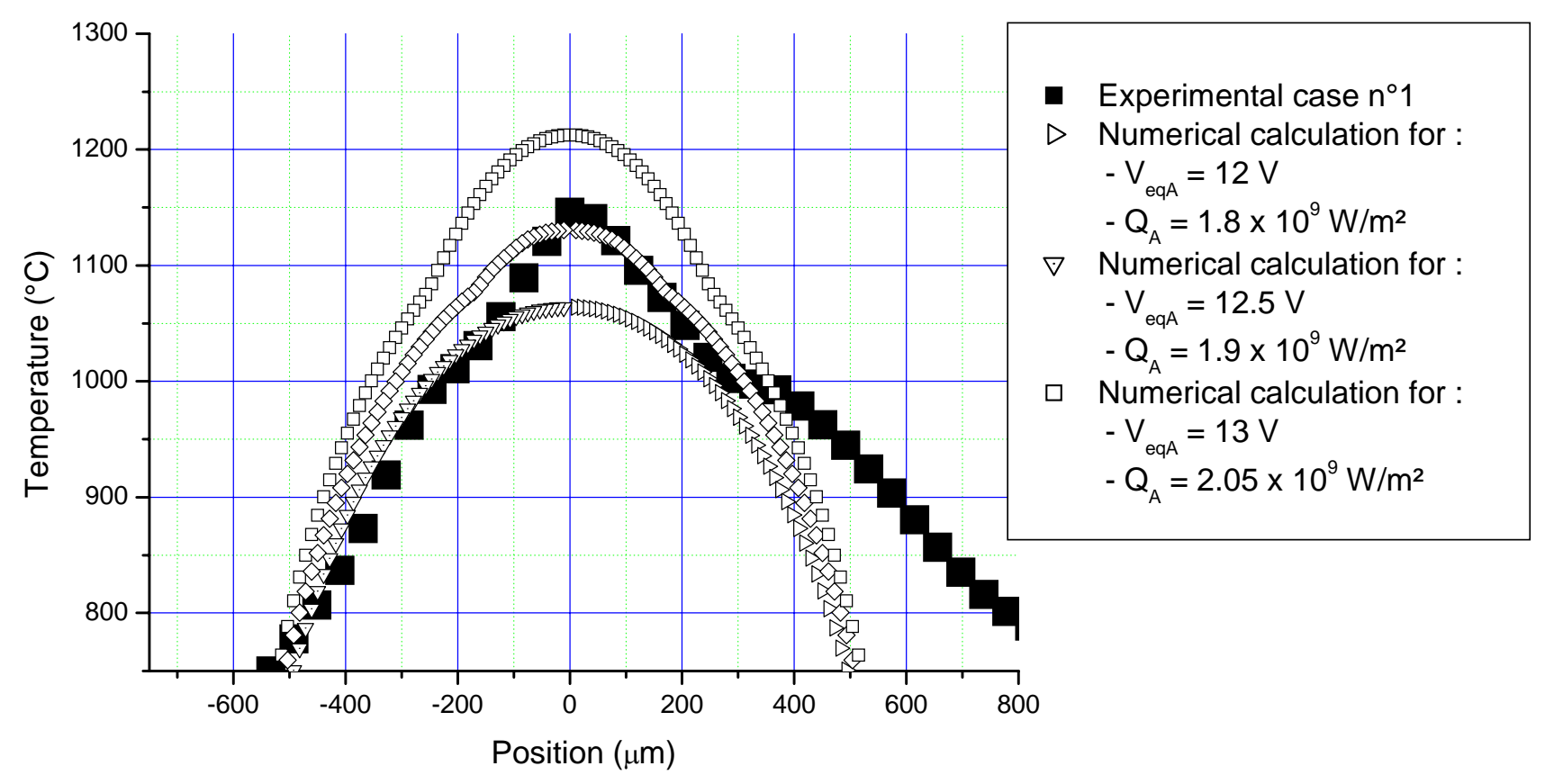

Figure 17. Experimental temperature profile in the case $n^{\circ} 1$ and three numerical results for three pairs $\left(\mathrm{V}_{\mathrm{eqA}}, \mathrm{Q}_{\mathrm{A}}\right)$

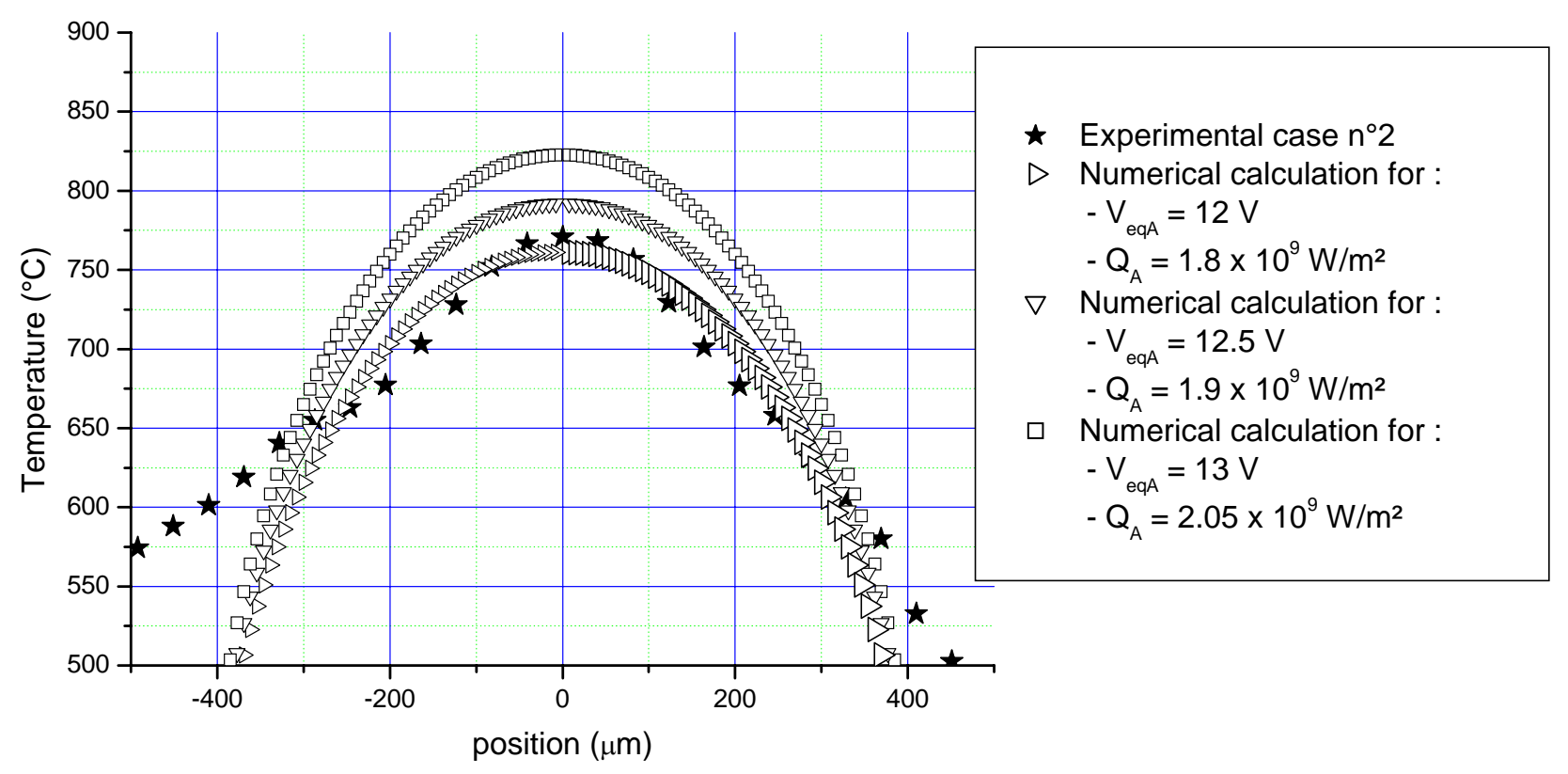

Figure 18. Experimental temperature profile in the case $n^{\circ} 2$ and three numerical results for three pairs $\left(\mathrm{V}_{\mathrm{eqA}}, \mathrm{Q}_{\mathrm{A}}\right)$ 
